\title{
Posterior approaches for symptomatic metastatic spinal cord compression
}

\author{
*Camilo Molina, MD, C. Rory Goodwin, MD, PhD, Nancy Abu-Bonsrah, BS, \\ Benjamin D. Elder, MD, PhD, Rafael De la Garza Ramos, MD, and Daniel M. Sciubba, MD \\ Department of Neurosurgery, Johns Hopkins University School of Medicine, Baltimore, Maryland
}

\begin{abstract}
Surgical interventions for spinal metastasis are commonly performed for mechanical stabilization, pain relief, preservation of neurological function, and local tumor reduction. Although multiple surgical approaches can be used for the treatment of metastatic spinal lesions, posterior approaches are commonly performed. In this study, the role of posterior surgical procedures in the treatment of spinal metastases was reviewed, including posterior laminectomy with and without instrumentation for stabilization, transpedicular corpectomy, and costotransversectomy. A review of the literature from 1980 to 2015 was performed using Medline, as was a review of the bibliographies of articles meeting preset inclusion criteria, to identify studies on the role of these posterior approaches among adults with spinal metastasis. Thirty-four articles were ultimately analyzed, including 1 randomized controlled trial, 6 prospective cohort studies, and 27 retrospective case reports and/or series. Some of the reviewed articles had Level II evidence indicating that laminectomy with stabilization can be recommended for improvement in neurological outcome and reduction of pain in selected patients. However, the use of laminectomy alone should be carefully considered. Additionally, transpedicular corpectomy and costotransversectomy can be recommended with the expectation of improving neurological outcomes and reducing pain in properly selected patients with spinal metastases. With improvements in the treatment paradigms for patients with spinal metastasis, as well as survival, surgical therapy will continue to play an important role in the management of spinal metastasis. While this review presents a window into determining the utility of posterior approaches, future prospective studies will provide essential data to better define the roles of the various options now available to surgeons in treating spinal metastases.
\end{abstract}

http://thejns.org/doi/abs/10.3171/2016.5.FOCUS16129

KEY WORDS spine metastasis; posterior approach; fusion; laminectomy; transpedicular corpectomy; costotransversectomy

$\mathrm{O}$ VER 1.4 million new cases of cancer are diagnosed each year in the United States, and it is expected that a subset of these patients will present with symptomatic metastatic lesions to the spinal column. ${ }^{1}$ The primary indications for surgical treatment of a metastatic spine lesion include mechanical stabilization, local tumor control, pain relief, and preservation of neurological function. ${ }^{29}$ Historically, the majority of surgically treated epidural spinal neoplasms were managed via decompressive posterior laminectomy (PL). However, decompressive laminectomy without instrumentation has many disadvan- tages including a failure to resolve anterior compression and the introduction or exacerbation of spinal instability. Given the shortcomings of decompressive laminectomy without instrumentation, circumferential decompression approaches became more prevalent. Today, surgical approaches are mostly chosen by their practicality in relation to the region of the affected spine (not all levels are equally accessible) and the goals of surgery. For example, metastatic spine lesions occurring ventrally in the subaxial cervical spine are best approached anteriorly. With similar reasoning, posterior transpedicular approaches are be-

ABBREVIATIONS ASIA = American Spinal Injury Association; $I / M=$ patients with improved or maintained; $M S C C=$ metastatic spinal cord compression; NAWPO = nonambulatory patients at presentation who walked postoperatively; $\mathrm{PCT}=$ posterolateral costotransversectomy approach; $\mathrm{PL}=$ posterior (approach) laminectomy; PTA = posterolateral transpedicular approach; RCT = randomized controlled trial; RR = recurrence rate; RT = radiotherapy; $\mathrm{SC}$ = surgical complication; SRS = stereotactic radiosurgery; VAS = visual analog scale; WPO = patients who could walk postoperatively.

SUBMITTED March 30, 2016. ACCEPTED May 23, 2016.

INCLUDE WHEN CITING DOI: 10.3171/2016.5.FOCUS16129.

* Drs. Molina and Goodwin contributed equally to this work. 
lieved to be technically more favorable in the treatment of tumors located in the thoracic spine, especially the mid- to upper thoracic spine, where the mediastinal contents make an anterior approach challenging.

There are a variety of posterior approaches for spinal metastases, including laminectomy with or without instrumentation for stabilization, transpedicular corpectomy, and costotransversectomy. Each approach is designed to address different clinical situations. A stand-alone laminectomy is generally considered only with metastatic involvement of the epidural space and lamina but is limited because it does not allow for decompression of ventral metastatic epidural spinal cord compression. Adding instrumentation for stabilization to a laminectomy can guard against instability due to tumor involvement of the facet joints, pedicles, or anterior vertebral body. The transpedicular corpectomy and costotransversectomy approaches provide the added benefit of ventrally decompressing the spinal cord or thecal sac and increasing the space between the lesion and the spinal cord for safer delivery of stereotactic radiosurgery (SRS). This is a significant advantage because the majority of spinal metastases occur ventrally in the vertebral body. ${ }^{29} \mathrm{~A}$ costotransversectomy involves more extensive resection and bone removal, with concurrent improved access to the anterior spinal column from a more lateral trajectory.

The goal of this review is to critically evaluate each posterior approach, consider the clinical context for which each is intended, and make recommendations based on evidence for the role of each approach in the management of metastatic spine disease.

\section{Methods \\ Search Strategy}

A review of the literature was performed using Medline and the bibliographies of the articles surveyed. The search query was broad and formulated to combine a number of subheadings and key words that included the interventions and pathology of interest. The search string employed was the following: "Spinal Neoplasms"[Mesh] OR "spine tumor"[All Fields] AND "metastatic"[All Fields] OR "metastases"[All Fields] OR "metastasis"[All Fields] OR "Neoplasm Metastasis"[Mesh] AND "surgery"[Subheading] OR "surgery"[All Fields] OR "surgical procedures, operative" [MeSH Terms] OR "surgical"[All Fields] AND "procedures"[All Fields] AND "operative"[All Fields] OR "operative surgical procedures"[All Fields] OR "surgery"[All Fields] OR "general surgery"[MeSH Terms] OR "general"'[All Fields] AND "surgery"[All Fields] OR "general surgery"[All Fields]. The following search was also coupled with OR "laminectomy"[All Fields], OR "transpedicular corpectomy"[All Fields], OR “costotransversectomy”[All Fields].

\section{Eligibility Criteria}

Criteria for possible inclusion were as follows: articles published between 1980 and 2015; all articles in English or with an English translation; articles with 8 or more subjects; articles with adult age groups (18 years and older); articles describing the use of a posterior surgical approach; articles describing the treatment of metastatic spine disease; and fully published peer-reviewed studies including randomized controlled trials (RCTs), nonrandomized trials, cohort studies, and case control studies. Both prospective and retrospective studies were considered.

Criteria for exclusion were the following: articles describing intradural spinal tumors or combining intradural spinal tumors with metastatic spinal tumors, articles describing primary spinal tumors or combining primary spinal tumors with metastatic spinal tumors, articles with pediatric age groups, articles reporting only surgical treatment of metastatic spine disease without noting clinical outcomes, articles describing only an anterior approach, articles with no extractable data specific to metastatic spine morbidity, and case reports.

\section{Results}

\section{Posterior Laminectomy With and Without Instrumentation}

Of the 34 articles selected for this review, 17 featured the use of a PL (Table 1). Authors of these papers reported neurological, survival, recurrence, pain, and complication outcomes. There was $1 \mathrm{RCT},{ }^{37} 2$ prospective cohort trials, ${ }^{14,22}$ and 14 retrospective case series. ${ }^{2,3,6,7,15,17,19,23,25-28,31}$

As regards neurological outcomes for laminectomy alone without instrumentation for stabilization, Class II data are provided by Young et al. ${ }^{37}$ In their RCT of 29 patients, laminectomy followed by radiotherapy (RT) was compared with RT alone for the treatment of spinal metastases. Inclusion criteria were a neurological symptom, myelographic extradural block, and tissue diagnosis of metastasis. Among the patients treated with laminectomy and RT, $3(50 \%)$ of 6 patients who were ambulatory before treatment remained ambulatory immediately after treatment and 4 (44\%) of 9 patients not ambulatory before treatment regained ambulation. One patient was paraplegic and did not become ambulatory. There was no significant difference in neurological outcomes when comparing laminectomy plus RT to RT alone. Pain alleviation was noted in $6(43 \%)$ of the 14 patients who had initially reported pain as a symptom and were treated with laminectomy and RT.

The study by Young et al. ${ }^{37}$ was an RCT but was considered Class II data for our analysis. Our biggest concern was the small sample size, which impaired the strength of any conclusions that could be reached from the data. Only 16 patients were treated with laminectomy and RT. When this cohort of patients was further divided into ambulatory and nonambulatory groups for statistical analysis, the sample sizes were less than 10 per group. With such small sample sizes, the power of the study was limited. Another concern about this study was the inclusion of 5 patients with lymphoma, which is typically not treated with surgical intervention now. Finally, the authors did not mention how many patients were evaluated for inclusion but not enrolled in the study, whether there was any crossover between treatment groups, or whether any patients were lost to follow-up.

The study by Patchell et al. ${ }^{24}$ also compared surgery in combination with RT to RT alone but had results pro- 
TABLE 1. Posterior laminectomy studies

\begin{tabular}{|c|c|c|c|}
\hline $\begin{array}{l}\text { Authors } \\
\& \text { Year }\end{array}$ & $\begin{array}{l}\text { Evidence } \\
\text { Class }\end{array}$ & $\begin{array}{l}\text { Design \& } \\
\text { Procedure }\end{array}$ & Outcome \\
\hline \multirow[t]{3}{*}{$\begin{array}{l}\text { Young et al., } \\
1980\end{array}$} & \multirow[t]{3}{*}{ II } & RCT, 29 patients & $\begin{array}{l}\text { NO (LWPO \& NAWPO): } 3 / 6(50 \%) \& 4 / 9(44 \%) \\
\text { immediately postop }\end{array}$ \\
\hline & & $\begin{array}{l}\text { Tumor origin: breast (6), lymphoma (5), lung (5), prostate (4), sarcoma (4) } \\
\text { melanoma (3), thyroid (1), lymphoepithelioma (1) }\end{array}$ & $\begin{array}{l}\text { PA (PR): } 6 / 14(43 \%) \text { had pain reduction (deter- } \\
\text { mined by reduced narcotic use) }\end{array}$ \\
\hline & & Procedure: 16 patients treated w/ laminectomy plus RT & $\begin{array}{l}\text { Complications: none } \\
\text { Survival: } 27.5 \text { wks }\end{array}$ \\
\hline \multirow{4}{*}{$\begin{array}{l}\text { Fuentes et } \\
\text { al., } 2007\end{array}$} & \multirow[t]{4}{*}{ II } & PCS, no comparison group, 14 patients & NO (I/M F): $100 \%$ \\
\hline & & $\begin{array}{l}\text { Tumor origin: mixed, cervical (21\%) \& breast }(21 \%) \text { carcinomas most } \\
\text { common }\end{array}$ & PA (PR): $100 \%$ patients reduced VAS scores \\
\hline & & Tumor location: T (78\%) \& L (22\%) & SCs: $0 \%$ \\
\hline & & $\begin{array}{l}\text { Procedure: } 14 \text { patients had same-session pst approach decompressive } \\
\text { laminectomy followed by pst instrumentation-assisted stabilization \& } \\
\text { open kyphoplasty }\end{array}$ & \\
\hline \multirow{4}{*}{$\begin{array}{l}\text { Mühlbauer } \\
\text { et al., } \\
2000\end{array}$} & \multirow[t]{4}{*}{ II } & PCS, no comparison group, 17 patients & NO (NI \& NAWPO): 82\% \& 70\% (7/10) \\
\hline & & Tumor origin: mixed, breast (27.4\%) \& lung (23.5\%) most common & Median survival: 10 mos \\
\hline & & Tumor location: T (70.5\%) most common & SCs \& MBL: 0\% \& $1595 \mathrm{ml}$ \\
\hline & & $\begin{array}{l}\text { Procedure: all } 17 \text { patients had circumferential decompression via single- } \\
\text { stage pst midline approach laminectomy w/ spinal reconstruction }\end{array}$ & \\
\hline \multirow{4}{*}{$\begin{array}{l}\text { Chaichana } \\
\text { et al., } \\
2008\end{array}$} & \multirow[t]{4}{*}{ III } & RCS, 78 patients & NO (WPO \& NAWPO): 78\% (61/78) \& 52\% (12/23) \\
\hline & & $\begin{array}{l}\text { Tumor origin: mixed, lung }(24 \%) \text {, prostate }(19 \%) \text {, breast }(17 \%) \text {, kidney } \\
(13 \%) \text {, most common }\end{array}$ & $\begin{array}{l}\text { SCs: nonambulatory patients incurred more } \\
\text { surgery-related postop SCs such as wound } \\
\text { dehiscence }(p=0.04) \& \text { CSF leak }(p<0.01)\end{array}$ \\
\hline & & Tumor location: T (54\%), L (27\%), \& C (19\%) & \\
\hline & & Procedure: all 78 patients had PL & \\
\hline \multirow{4}{*}{$\begin{array}{l}\text { Kondo et } \\
\text { al., } 2008\end{array}$} & \multirow[t]{4}{*}{ III } & RCS, 96 patients & NO (WPO \& I/M F): 88\% \& 89\% \\
\hline & & $\begin{array}{l}\text { Tumor origin: mixed, breast }(18.8 \%) \text {, intestine }(12.5 \%), \text { \& prostate }(11.4 \%) \\
\text { most common }\end{array}$ & $\begin{array}{l}\text { Median survival: } 17 \text { mos } \\
\text { RR: } 6 \% \\
\text { PA (PR): } 60 \%\end{array}$ \\
\hline & & Tumor location: T (92.7\%) most common & $\begin{array}{l}\text { Complications (SCs, MBL, \& median blood loss): } \\
15 \%, 880 \mathrm{ml}, 590 \mathrm{ml}\end{array}$ \\
\hline & & Procedure: all patients had intraop RT plus PL \& stabilization & \\
\hline \multirow{4}{*}{$\begin{array}{l}\text { Placantona- } \\
\text { kis et al., } \\
2008\end{array}$} & \multirow[t]{4}{*}{ III } & RCS, 90 patients & NO (improved ASIA): $32 \%$ patients \\
\hline & & Tumor origin: mixed, sarcomas most common & Median survival: 10 mos \\
\hline & & $\begin{array}{l}\text { Tumor location: cervicothoracic junction most common (tumor btwn C-6 } \\
\text { \& T-3) }\end{array}$ & PA (PR): $63 \%$ \\
\hline & & $\begin{array}{l}\text { Procedure: } 70 \text { patients w/ metastatic spine disease had posterolat lami- } \\
\text { nectomy including unilat or bilat facetectomy \& pst instrumentation } \\
\text { following resection of cervicothoracic junction tumors }\end{array}$ & SCs: $19 \%$ \\
\hline \multirow{4}{*}{$\begin{array}{l}\text { Jansson \& } \\
\text { Bauer, } \\
2006\end{array}$} & \multirow[t]{4}{*}{ III } & RCS, 282 patients & NO (I/M F): 95\% \\
\hline & & Tumor origin: mixed, prostate (40\%) \& breast $(15 \%)$ most common & RR: $6 \%$ \\
\hline & & Tumor location: T (78\%) \& L (22\%) & $\begin{array}{l}\text { Survival: } 63 \% \text { survive at } 3 \text { mos, } 26 \% \text { at } 12 \text { mos, } \\
13 \% \text { at } 24 \text { mos }\end{array}$ \\
\hline & & $\begin{array}{l}\text { Procedure: } 212 \text { patients had pst decompression laminectomy w/ stabili- } \\
\text { zation }\end{array}$ & SCs: $25 \%$ \\
\hline \multirow{4}{*}{$\begin{array}{l}\text { Saito et al., } \\
\quad 2006\end{array}$} & \multirow[t]{4}{*}{ III } & RCS, 79 patients & NO (NAWPO \& I F): 78\% (45/58) \& 86\% \\
\hline & & $\begin{array}{l}\text { Tumor origin: mixed, breast (11\%), lung }(10 \%), \& \text { colon }(8 \%) \text { most com- } \\
\text { mon }\end{array}$ & Mean survival: 10.4 mos \\
\hline & & $\begin{array}{l}\text { Tumor location: T (76\%), thoracolumbar (11\%), cervicothoracic }(9 \%), \& \text { C } \\
(4 \%)\end{array}$ & RR: $2.5 \%$ \\
\hline & & $\begin{array}{l}\text { Procedure: all } 79 \text { patients had PL \& resection of epidural metastatic } \\
\text { tumor w/ intraop RT }\end{array}$ & Complications (MBL): $934 \mathrm{ml}$ \\
\hline
\end{tabular}


» CONTINUED FROM PAGE 3

TABLE 1. Posterior laminectomy studies

\begin{tabular}{|c|c|c|c|}
\hline $\begin{array}{l}\text { Authors } \\
\& \text { Year }\end{array}$ & $\begin{array}{l}\text { Evidence } \\
\text { Class }\end{array}$ & $\begin{array}{l}\text { Design \& } \\
\text { Procedure }\end{array}$ & Outcome \\
\hline \multirow[t]{4}{*}{$\begin{array}{l}\text { North et al., } \\
2005\end{array}$} & \multirow[t]{4}{*}{ III } & RCS, 61 patients & $\begin{array}{l}\text { NO (WPO): } 96.7 \% \text {; ambulatory status endured } \\
\text { significantly longest in patients w/ breast } \\
\text { cancer }(p=0.013)\end{array}$ \\
\hline & & Tumor origin: mixed, breast (18\%) \& lung (16.4\%) most common & $\begin{array}{l}\text { Median survival: } 10 \text { mos; survival stratified based } \\
\text { on tumor identity \& median survival ranged } \\
\text { from } 1.7 \text { yrs in patients w/ breast cancer to } 3 \\
\text { mos in those w/ lung cancer }\end{array}$ \\
\hline & & Tumor location: T (47\%), L (32\%), \& C (21\%) & PA (PR): $56 \%$ \\
\hline & & $\begin{array}{l}\text { Procedure: } 24 \text { patients had PL \& } 13 \text { had PL w/ fusion or placement of } \\
\text { instrumentation }\end{array}$ & Complications (SCs \& IODs): $8.1 \%$ \& 2 \\
\hline \multirow{3}{*}{$\begin{array}{l}\text { Chen et al., } \\
2007\end{array}$} & \multirow[t]{3}{*}{ III } & RCS, 70 patients & NO (NAWPO): $70.4 \%(38 / 54)$ \\
\hline & & $\begin{array}{l}\text { Tumor origin: mixed, breast (18.5\%), liver (14.2\%), \& thyroid (11.4\%) most } \\
\text { common }\end{array}$ & Survival: $87 \%$ survive at 3 mos, $70 \%$ at 6 mos \\
\hline & & $\begin{array}{l}\text { Procedure: all } 70 \text { patients had PL \& subsequent stabilization w/ instru- } \\
\text { mentation }\end{array}$ & $\begin{array}{l}\text { RR: } 8.5 \% \\
\text { PA (PR): } 78.3 \% \\
\text { SCs: } 0 \%\end{array}$ \\
\hline \multirow[t]{3}{*}{$\begin{array}{l}\text { Hirabayashi } \\
\text { et al., } \\
2003\end{array}$} & \multirow[t]{3}{*}{ III } & RCS, 81 patients & $\begin{array}{l}\text { NO (WPO \& LWPO): } 70 \% \text {; stratified for LWPO } \\
\text { based on tumor pathology; longest ambulation } \\
\text { time observed for different cancer types: my- } \\
\text { eloma (median } 44.1 \text { mos), prostate carcinoma } \\
\text { ( } 22.6 \text { mos), thyroid ( } 21.4 \text { mos), lung ( } 14.0 \text { mos), } \\
\text { \& liver ( } 7.9 \text { mos) }\end{array}$ \\
\hline & & $\begin{array}{l}\text { Tumor origin: mixed, liver (15\%) \& prostate }(15 \%) \text { most common } \\
\text { Tumor location: } \mathrm{T}(72 \%), \mathrm{L}(15 \%), \mathrm{C}(12 \%), \& \mathrm{~S}(1 \%) \\
\text { Procedure: } 24 \text { patients had palliative surgery that included tumor resec- } \\
\text { tion \& decompression of spinal cord w/ PL w/ or w/o instrumentation }\end{array}$ & $\begin{array}{l}\text { Median survival: } 10.6 \text { mos; stratified for survival } \\
\text { based on tumor pathology: myeloma ( } 44.4 \\
\text { mos), thyroid carcinoma ( } 25.5 \text { mos), prostate } \\
\text { carcinoma ( } 20.1 \text { mos), breast carcinoma ( } 18.6 \\
\text { mos), rectal carcinoma ( } 15.2 \text { mos), primary } \\
\text { tumor in pancreas ( } 5.7 \text { mos), esophagus ( } 4.7 \\
\text { mos), \& stomach ( } 2.1 \text { mos); patients w/ } \\
\text { myeloma, thyroid carcinoma, or prostate car- } \\
\text { cinoma lived significantly longer than patients } \\
\text { w/ primary tumors in esophagus, liver, lung, or } \\
\text { pancreas (p<0.05) }\end{array}$ \\
\hline & & & $\begin{array}{l}\text { RR: } 21 \% \\
\text { PA (PR): } 77 \%\end{array}$ \\
\hline \multirow[t]{5}{*}{$\begin{array}{l}\text { Rompe et } \\
\quad \text { al., } 1999\end{array}$} & \multirow[t]{5}{*}{ III } & RCS, 106 patients & $\begin{array}{l}\text { NO (NI, I/M F, \& WPO): } 62.5 \% ; 95 \%, \& 79 \% \text { after } \\
1 \mathrm{yr}\end{array}$ \\
\hline & & $\begin{array}{l}\text { Tumor origin: mixed, breast (29\%), lung (19\%), \& kidney (15\%) most } \\
\text { common }\end{array}$ & $\begin{array}{l}\text { Mean survival: } 19.2 \text { mos; } 72 \%(76 / 106) \text { survive at } \\
\quad 6 \text { mos; } 50 \%(53 / 106) \text { survive at } 12 \text { mos }\end{array}$ \\
\hline & & Tumor location: 259 affected vertebrae; T (56\%), L (34\%) \& C (10\%) & RR: $5.6 \%$ \\
\hline & & $\begin{array}{l}\text { Procedure: all } 106 \text { had PL w/ subsequent stabilization w/ Cotrel-Dubous- } \\
\text { set instrumentation }\end{array}$ & $\begin{array}{l}\text { PA: VAS score decreased from } 7.8 \text { to } 3.2 \text { at } \\
\text { postop }\end{array}$ \\
\hline & & & SCs: $12 \%$ \\
\hline \multirow{4}{*}{$\begin{array}{l}\text { Shimizu et } \\
\text { al., } 1992\end{array}$} & \multirow[t]{4}{*}{ III } & RCS, 11 patients & NO (NI): 82\% (9/11) \\
\hline & & Tumor origin: mixed, breast (36\%) \& gastric $(36 \%)$ most common & RR: $18 \%$ \\
\hline & & Tumor location: C, T, \& L & PA (PR): $100 \%$ \\
\hline & & Procedure: all 11 patients had PL w/ stabilization & Complications (MBL): $3000 \mathrm{ml}$ \\
\hline
\end{tabular}


» CONTINUED FROM PAGE 4

TABLE 1. Posterior laminectomy studies

\begin{tabular}{|c|c|c|c|}
\hline $\begin{array}{l}\text { Authors } \\
\& \text { Year }\end{array}$ & $\begin{array}{l}\text { Evidence } \\
\text { Class }\end{array}$ & $\begin{array}{l}\text { Design \& } \\
\text { Procedure }\end{array}$ & Outcome \\
\hline \multirow{3}{*}{$\begin{array}{l}\text { Bach et al., } \\
\quad 1992\end{array}$} & \multirow[t]{3}{*}{ III } & RCS, 102 patients & $\mathrm{NO}$ (NI): PL $=48 \%, \mathrm{RT}=46 \%, \mathrm{PL}+\mathrm{RT}=67 \%$ \\
\hline & & Tumor origin: lung carcinoma & $\begin{array}{l}\text { Survival: patients treated w/ PL+RT had better sur- } \\
\text { vival (median } 3.5 \text { mos, range } 0-132 \text { mos) than } \\
\text { patients treated w/ either PL (median } 1.5 \text { mos, } \\
\text { range } 0-32 \text { mos) or RT (median } 1 \text { mo, range } \\
0-59 \text { mos) alone ( } p=0.03 \text {, log-rank test) }\end{array}$ \\
\hline & & Procedure: patients divided into 3 groups: PL, RT, or PL followed by RT & PA (PR): $100 \%$ \\
\hline \multirow{3}{*}{$\begin{array}{l}\text { Bach et al., } \\
\quad 1990\end{array}$} & \multirow[t]{3}{*}{ III } & RCS, 398 patients & $\mathrm{NO}(\mathrm{NI}): \mathrm{PL}=44 \%, \mathrm{RT}=35 \%, \mathrm{PL}+\mathrm{RT}=59 \%$ \\
\hline & & Tumor origin: lung (18\%), prostate $(19 \%), \&$ breast $(14 \%)$ carcinomas & $\begin{array}{l}\text { Median survival: } \mathrm{PL}=2.8 \mathrm{mos}, \mathrm{RT}=2.3 \mathrm{mos} \\
\mathrm{PL}+\mathrm{RT}=5.4 \mathrm{mos}\end{array}$ \\
\hline & & Procedure: PL, RT, or PL+RT & \\
\hline \multirow{3}{*}{$\begin{array}{l}\text { Yang et al., } \\
2012\end{array}$} & \multirow[t]{3}{*}{ III } & RCS, 217 patients & \multirow{3}{*}{$\begin{array}{l}\text { Median survival: PL w/o instrumentation } 5.0 \text { mos, } \\
\text { PL w/ instrumentation } 9.0 \text { mos }\end{array}$} \\
\hline & & $\begin{array}{l}\text { Tumor origin: mixed, lung }(20 \%) \text {, colorectal }(12 \%), \& \text { breast }(11 \%) \text { most } \\
\text { common }\end{array}$ & \\
\hline & & $\begin{array}{l}\text { Procedure: patients divided into } 4 \text { groups: PL w/o instrumentation, PL w/ } \\
\text { instrumentation, corpectomy w/ ant fusion, corpectomy w/ pst fusion }\end{array}$ & \\
\hline \multirow{3}{*}{$\begin{array}{l}\text { Rades et } \\
\quad \text { al., } 2011\end{array}$} & \multirow[t]{3}{*}{ III } & Retrospective matched-pair analysis, 67 patients & $\mathrm{NO}(\mathrm{NI}): \mathrm{PL}+\mathrm{RT}=22 \%$ \\
\hline & & $\begin{array}{l}\text { Tumor origin: lung cancer ( } 54 \%) \text {, cancer of unknown primary origin } \\
(19 \%) \text {, renal cell }(13 \%) \text {, colorectal }(13 \%)\end{array}$ & $\begin{array}{l}\text { Local control rate: } \mathrm{PL}+\mathrm{RT}=93 \% \text { at } 6 \mathrm{mos}, \mathrm{PL}+\mathrm{RT} \\
\quad=85 \% \text { at } 12 \mathrm{mos}\end{array}$ \\
\hline & & Procedure: 24 patients had PL followed by RT vs RT alone & $\begin{array}{l}\text { Median survival: } P L+R T=50 \% \text { at } 6 \text { mos, } P L+R T= \\
38 \% \text { at } 12 \text { mos }\end{array}$ \\
\hline
\end{tabular}

Ant = anterior; $\mathrm{C}=$ cervical spine; $\mathrm{F}=$ Frankel grade; $\mathrm{I}=$ improved; $\mathrm{I} F=$ patients with at least one-grade improvement in Frankel grade; $I O D=$ intraoperative death; $L=$ lumbar spine; $\mathrm{LWPO}=$ length of time walking ability retained postoperation; $\mathrm{M}=$ maintained; $\mathrm{MBL}=$ mean blood loss; $\mathrm{NI}=$ patients with neurological improvement; $\mathrm{NO}=$ neurological outcome; $\mathrm{PA}=$ pain alleviation outcome; $\mathrm{PCS}=$ prospective cohort series; $\mathrm{PR}=$ patients with pain relief; pst = posterior; $\mathrm{RCS}=$ retrospective case series; $\mathrm{T}$ $=$ thoracic spine; $\mathrm{VAS}=$ visual analog scale.

foundly different from those of Young et al. ${ }^{37}$ However, Patchell and colleagues did not provide any outcome data specific to surgical approaches; therefore, their study was not useful for our analysis of specific surgical approaches.

Class II evidence was available from 2 prospective studies of laminectomy with instrumentation. Fuentes et al. ${ }^{14}$ evaluated outcomes in 14 patients with vertebral metastatic lesions who underwent a posterior approach decompressive laminectomy followed by posterior instrumentation-assisted stabilization and open kyphoplasty. These authors reported the percentage of patients with improved or maintained (I/M) Frankel grades (100\%). ${ }^{14}$ Mühlbauer et al.22 (17 patients) evaluated circumferential decompression through a single-stage posterior midline approach laminectomy with spinal reconstruction. ${ }^{22}$ The reported neurological outcomes were overall percentage of patients with neurological improvement (82\%) and percentage of nonambulatory patients at presentation who walked postoperatively (NAWPO; 70\%). ${ }^{22}$

Class III evidence was available from the 14 remaining retrospective studies selected, all case series except for a matched-pair analysis. Five of these 14 retrospective series used a PL only, without stabilization instrumentation. Bach et al. ${ }^{3}$ (398 patients) evaluated different treatments to reduce metastatic spinal cord compression (MSCC). They divided the patients into treatment groups: PL, RT, or PL followed by RT (PL+RT). ${ }^{3}$ The percentage of pa- tients who experienced neurological improvement was as follows: $\mathrm{PL}=44 \%, \mathrm{RT}=35 \%, \mathrm{PL}+\mathrm{RT}=59 \% .^{3} \mathrm{In}$ a follow-up study, Bach et al. evaluated outcomes in patients experiencing MSCC due to lung carcinoma and found similar data when comparing the efficacy of PL with that of RT $(\mathrm{PL}=48 \%, \mathrm{RT}=46 \%, \mathrm{PL}+\mathrm{RT}=67 \%) .{ }^{2}$ Chaichana et al. ${ }^{6}$ (78 patients) evaluated the use of PL on metastatic epidural spinal cord compression based on tumor location and the patient's circumstances. ${ }^{6}$ Of the 55 patients who were able to ambulate preoperatively, 24 (44\%) underwent a PL. Twenty-three patients were unable to ambulate preoperatively, and 19 (83\%) underwent a PL. The remaining patients underwent other approaches. Chaichana et al. did not specifically indicate outcomes for the patents who had the PL; however, they did report overall postoperative ambulatory outcomes for the patients who could walk preoperatively (patients who could walk postoperatively [WPO]: 78\%) and for those who were nonambulatory preoperatively (NAWPO: 52\%). ${ }^{6}$ In the study by North et al. ${ }^{23}$ (61 patients), 24 patients underwent laminectomy with a posterior approach and 13 underwent laminectomy with fusion or placement of instrumentation. The authors did not specifically report the surgical outcomes but they did report the WPO as $96.7 \%$ and the WPO at 6 months as $81 \%$. They also stratified ambulatory status according to cancer type and reported significantly longer retention of ambulation among patients afflicted with breast cancer $(\mathrm{p}$ 
$=0.013)$. The study by Rades et al. ${ }^{26}$ also compared surgery in combination with RT to RT alone for "unfavorable" tumors (non-small cell lung cancer, cancer of unknown primary origin, renal cell cancer, and colorectal cancer). Their results were also different from those of Patchell et al., and they concluded that PL with RT was no different from RT alone in terms of ambulatory status following treatment, local control, or survival at 6 and 12 months. ${ }^{24}$ Twenty-four patients underwent laminectomy and RT in this matched-pair analysis.

Seven of the retrospective case series reported on the use of PL with stabilization. Rompe et al. ${ }^{27}$ (106 patients) evaluated the outcome of PL plus subsequent stabilization with Cotrel-Dubousset instrumentation. The number of patients who underwent PL was not reported; however, the authors noted that the most common operative treatment was PL and resection of the facet joints, including the removal of osseous or tumorous masses. Overall neurological outcomes were reported: neurological improvement, 62.5\%; I/M Frankel grades, 95\%; and WPO after 1 year, $79 \% .{ }^{27}$ In the study by Hirabayashi et al. ${ }^{15}$ (81 patients), 24 patients underwent palliative surgery that included tumor resection and decompression of the spinal cord together with PL with or without instrumentation. They reported an overall WPO of 70\%; however, they also stratified ambulatory status based on cancer type and reported the longest ambulation time for patients with myeloma (median 44.1 months). The remaining median ambulation times were as follows: prostate carcinoma (22.6 months), thyroid carcinoma (21.4 months), lung carcinoma (14.0 months), and liver carcinoma (7.9 months). Hirabayashi et al. also noted that patients who had "favorable" primary tumors (for example, prostate, bone marrow, thyroid) had longer median ambulation times (22.4 months) than those with "unfavorable" tumors such as lung, liver, breast, rectal, kidney, gastrointestinal, and pancreatic cancers (6.9 months; $\mathrm{p}<0.0001)$. In the study by Jansson and Bauer ${ }^{17}$ (282 patients), a group of 212 patients with neurological deficits due to thoracic or lumbar spinal metastases were evaluated after undergoing posterior decompressive laminectomy with stabilization; the remaining patients were managed with various other approaches. The authors did not specifically report neurological outcomes for the posterior approach, although the overall neurological outcome in terms of I/M Frankel grades was 95\%. Chen et al. (70 patients) described the use of palliative surgery via PL and subsequent stabilization with instrumentation for MSCC. The measured outcomes were patients with neurological improvement (70.4\%) and increased activity in bedridden patients $(60 \%)$. Placantonakis et al..$^{25}$ (90 patients) evaluated the outcomes of 70 patients with metastatic spine disease who had undergone posterolateral laminectomy including uni- or bilateral facetectomy and posterior instrumentation following resection of cervicothoracic junction tumors. The percentage of patients who had improved American Spinal Injury Association (ASIA) grades was $32 \%$. Shimizu et al. ${ }^{31}$ (11 patients) reported on the use of PL with stabilization for multiple metastatic tumors of the spine. The reported outcomes were neurological improvement $(82 \%)$ and neurological deterioration $(0 \%)$. Yang et al. (217 patients) analyzed the prognostic factors associ- ated with survival time after a spinal metastasis operation and found that patients who underwent decompressive laminectomy without instrumentation had a median survival of 5.0 months, whereas those who underwent decompressive laminectomy with instrumentation had a median survival of 9.0 months, and the difference between the two was not significant. ${ }^{36}$ These authors also analyzed anterior corpectomy and did not stratify survival, complications, functional status, or other factors by tumor type or operation.

Two of the retrospective case series used a posterior approach with intraoperative RT. Kondo et al. ${ }^{19}$ (96 patients) evaluated the use of intraoperative RT combined with a PL and stabilization in patients with nonambulatory paralysis due to metastatic spine disease. The reported outcomes were WPO (88\%) and I/M Frankel grades (89\%). ${ }^{19}$ Saito et al. ${ }^{28}$ (79 patients) evaluated the outcomes of PL and resection of an epidural metastatic tumor with intraoperative RT for the treatment of spinal metastasis. The reported outcomes were improvement by at least one Frankel grade $(86 \%)$ and NAWPO (78\%). ${ }^{28}$

Thirteen of the 17 studies addressing the use of PL reported survival data. Young et al. reported a mean survival of 27.5 weeks for patients who underwent laminectomy. ${ }^{37}$ Of the 2 prospective studies on PL, only the one by Mühlbauer et al. reported a median survival outcome, which was 10 months. ${ }^{22}$ Twelve of the 13 retrospective case series reported survival outcomes. Bach et al. ${ }^{3}$ found that survival was best for patients treated with both PL and RT, reporting median survival times of 2.8 months following PL, 2.3 months following RT, and 5.4 months following PL+RT. In a follow-up study, these same authors $^{2}$ evaluated outcomes for lung carcinoma and revealed similar results, showing median survival times of 1.5 months after PL, 1 month after RT, and 3.5 months after PL+RT. The remaining studies reported overall median survival time (17 months ${ }^{19} 10$ months, ${ }^{25} 10.6$ months,${ }^{15}$ 10 months $\left.^{23}\right)$, mean survival time (19.2 months, ${ }^{27} 10.4$ month ${ }^{28}$ ), or overall survival of patients at the 3-month follow-up $\left(87 \%,{ }^{7} 63 \%{ }^{17}\right)$. North et al. reported an overall median survival of 10 months and also stratified survival based on tumor pathology, documenting a median survival of 1.7 years in breast cancer patients (HR 0.348, p $=0.02$ ) and 3 months in lung cancer patients. ${ }^{23}$ Although Hirabayashi et al. documented an overall median survival of 10.6 months, they also stratified survival outcomes according to tumor pathology and reported that myeloma (44.4 months), thyroid carcinoma (25.5 months), prostate carcinoma (20.1 months), breast carcinoma (18.6 months), rectal carcinoma (15.2 months), primary tumor in the pancreas (5.7 months), esophagus (4.7 months), and stomach (2.1 months) had shorter median survivals. Patients with myeloma, thyroid carcinoma, or prostate carcinoma had significantly longer survival than patients with primary tumors in the esophagus, liver, lung, or pancreas ( $p$ $<0.05) .{ }^{15}$ Univariate analysis showed that the anatomical site of the primary tumor, postoperative ambulation, and combined adjuvant therapy (chemotherapy plus RT) were associated with prolonged survival $(p<0.05)$. Multivariate analysis revealed that the primary tumor site and postoperative ambulatory function were independent predic- 
tors of prolonged survival $(\mathrm{p}<0.0001)$. There were also significant correlations between ambulation time and survival time in patients who were able to walk postsurgery ( $p<0.0001)$, even in patients with liver $(\mathrm{p}<0.05)$ or lung carcinoma $(\mathrm{p}<0.05)$.

With respect to recurrence outcomes, 8 of the 17 publications reported data for patients' recurrence rates (RRs): $21 \%,{ }^{15} 18 \%,{ }^{31} 8.5 \%,{ }^{7} 6 \%,{ }^{17,19} 5.6 \%,{ }^{27} 2.5 \% .^{28}$ Rades et al. ${ }^{26}$ reported a local control rate of $93 \%$ at 6 months and $85 \%$ at 12 months. As regards pain alleviation outcomes, 10 of the 17 papers reported relevant data. The RCT by Young et al. ${ }^{37}$ did not directly measure pain reduction; however, the investigators did note that patients in the surgery plus RT group had reduced use (38\% improvement) of narcotic analgesics. Of the 2 prospective studies, only one reported a pain outcome, indicating that $100 \%$ of the patients had reduced scores on the visual analog scale (VAS) for pain. ${ }^{14}$ Nine of the 17 PL case series assessed pain outcomes and reported overall percentages of patients with pain relief $\left(100 \%, 2,14,3178.3 \%,{ }^{7} 77 \%,{ }^{15} 63 \%,{ }^{25} 60 \%,{ }^{19} 56 \%,{ }^{23} 43 \%{ }^{37}\right)$. Overall patient VAS scores decreased from a mean score of 7.8 to 3.2 in the study by Rompe et al. ${ }^{27}$

As regards complications, 12 of the 17 studies reported complication outcomes. The RCT by Young et al. ${ }^{37}$ noted no complications. The 2 prospective studies reported $0 \%$ surgical complications (SCs) in their cases. ${ }^{14,22}$ Eight of the 14 retrospective case series reported complications, the most common being SCs $\left(25 \%,{ }^{17} 19 \%,{ }^{25} 15 \%,{ }^{19} 12 \%,{ }^{27}\right.$ $8.1 \%,{ }^{23}$ and $\left.0 \%{ }^{7}\right)$. The study by Chaichana et al. reported that nonambulatory patients incurred more surgery-related postoperative complications, namely wound dehiscence ( $\mathrm{p}$ $=0.04)$ and cerebrospinal fluid leakage $(\mathrm{p}<0.01){ }^{6}$

In all 17 publications, a PL was used based on the location of the tumor and the surgeon's familiarity with the approach and reconstructive options. 2,3,6,7,14,15,17,19,22,23,25-28,31,36,37 Posterior approach laminectomy with instrumentation was used to stabilize the spine in 11 studies. ${ }^{7,14,15,17,19,22,24,25,27,31} \mathrm{~A}$ PL was used with intraoperative RT to treat residual spinal metastatic tumor in 2 studies due to the severity of the spinal metastases. ${ }^{19,28}$

\section{Transpedicular Corpectomy}

Of the 34 publications selected for this review, 14 documented the use of the posterolateral transpedicular approach (PTA; Table 2). Of note, Laufer et al. analyzed local tumor control using the same data set as Wang et al..$^{20,33}$ These papers provided results for neurological outcomes, survival, recurrence, pain, and complication rates. There were 3 prospective cohort trials ${ }^{32,33,38}$ and 11 retrospective

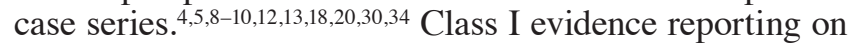
the use of PTAs was not available from any of the selected articles.

As regards neurological outcomes, Class II evidence was available and provided by 3 prospective studies by Street et al., ${ }^{32}$ Wang et al., ${ }^{33}$ and Zairi et al. ${ }^{38}$ The study by Street et al. (42 patients) sought to evaluate single-stage posterolateral vertebrectomy for disease of the lumbar spine or combined bilateral costotransversectomies in the thoracic spine. ${ }^{32}$ The neurological outcome reported was neurological improvement (100\%). Wang et al. (140 patients) investigated the use of single-stage PTA with in- strumentation for the resection of epidural metastatic spine tumors involving the vertebral body with circumferential reconstruction. ${ }^{33}$ They reported the neurological outcomes of neurological improvement (90\%), NAWPO (75\%), and I/M ASIA grades postoperatively (96\%). Zairi et al. (10 patients) performed a prospective evaluation of minimally invasive transpedicular vertebrectomy and spinal cord decompression and stabilization using a tubular expandable retractor for the palliative management of symptomatic thoracolumbar spine metastasis. ${ }^{38}$ These authors reported no intraoperative complications and one patient with a urinary tract infection postoperatively. Eight patients $(80 \%)$ improved at least 1 Frankel grade, and all patients had pain improvement. The mean follow-up was 10.1 months, and $40 \%$ of the patients died within that period of time. The authors concluded that minimally invasive treatment of thoracolumbar metastasis was safe and effective in patients with limited life expectancy.

Class III evidence was provided by the 11 remaining retrospective case series reporting on PTAs. Bilsky et al. ${ }^{4}$ (25 patients) evaluated PTA for spondylectomy, epidural decompression, and circumferential fusion of spinal metastases to decompress and instrument the anterior and posterior spine. The neurological outcomes measured were neurological improvement (25\%) and WPO (100\%). Chen et al. ${ }^{8}$ (31 patients) reported outcomes of PTA or combined posterior and anterior surgical results of MSCC secondary to non-small cell lung cancer. Twenty-eight of the 31 patients underwent PTA. The reported outcomes were WPO (74\%) and improved Frankel grades (80\%). A follow-up study by Chen et al. ${ }^{9}$ (23 patients) used transpedicular partial corpectomy without anterior vertebral reconstruction to treat thoracic spinal metastases. The neurological outcomes reported were WPO $(73.9 \%)$ and improved Frankel grades $(82.6 \%)$. Cho and $\operatorname{Sung}^{10}$ (21 patients) evaluated palliative surgery for metastatic thoracic and lumbar tumors using PTA with posterior instrumentation and reported one neurological outcome (improved Frankel grades 33\%). Deutsch et al. ${ }^{12}$ (8 patients) evaluated minimally invasive posterolateral vertebrectomy and decompression for metastatic disease to the thoracic spine in patients unsuitable for an open anterior approach. The reported neurological outcome was patients with improvement by at least 1 grade on the Nurick scale $(62.5 \%)$. Kamat et al. ${ }^{18}$ (8 patients) evaluated single-stage PTA for circumferential epidural decompression and 3-column stabilization using a titanium cage for upper thoracic spine neoplastic disease and reported one neurological outcome (I/M Frankel grades 100\%). Senel et al. ${ }^{30}$ (7 patients) evaluated circumferential stabilization with ghost screwing (that is, the creation of an acrylic anterior graft that is directly connected to the posterior transpedicular stabilizing system via 2 ghost screws) after posterior resection of spinal metastases via a transpedicular route. They reported that neurological function remained unchanged for all patients not lost to follow-up. Weller and Rossitch ${ }^{34}$ (8 patients) evaluated unilateral posterolateral decompression without stabilization for neurological palliation of symptomatic spinal metastasis in debilitated patients. All patients with preoperative motor deficits demonstrated increased motor strength postoperatively, and all were able to ambulate either independently or with the 
TABLE 2. Transpedicular corpectomy studies

\begin{tabular}{|c|c|c|c|}
\hline $\begin{array}{l}\text { Authors } \\
\text { \& Year }\end{array}$ & $\begin{array}{l}\text { Evidence } \\
\text { Class }\end{array}$ & Design \& Procedure & Outcome \\
\hline \multirow{5}{*}{$\begin{array}{c}\text { Street } \\
\text { et al., } \\
2007\end{array}$} & \multirow[t]{5}{*}{ II } & PCS, nonrandomized, 42 patients & NO (NI): $100 \%$ \\
\hline & & Tumor origin: mixed, breast (21\%), kidney (19\%) \& lung (14\%) most common & $\begin{array}{l}\text { Survival: } 75 \% \text { survive at } 6 \text { mos, } 50 \% \text { survive at } \\
12 \text { mos }\end{array}$ \\
\hline & & Tumor location: T (81\%) \& L (19\%) & RR: $2.4 \%$ \\
\hline & & \multirow[t]{2}{*}{ Procedure: all patients had SPLV plus PCT } & PA (PR): $100 \%$ \\
\hline & & & SCs: $26 \%$ \\
\hline \multirow{5}{*}{$\begin{array}{l}\text { Wang } \\
\text { et al., } \\
2004\end{array}$} & \multirow[t]{5}{*}{ II } & PCS, no comparison, 140 patients & NO (NI, NAWPO, \& I/M ASIA): 90\%, 75\%, \& 96\% \\
\hline & & Tumor origin: mixed, renal (21\%), lung (18\%), \& colon $(11 \%)$ most common & Median survival: 7.7 mos \\
\hline & & Tumor location: T (80\%) \& L (20\%) & RR: $11 \%$ \\
\hline & & \multirow{2}{*}{$\begin{array}{l}\text { Procedure: all patients had single-stage PTA to decompress spine circum- } \\
\text { ferentially \& place instrumentation }\end{array}$} & PA (PR): $96 \%$ \\
\hline & & & $\begin{array}{l}\text { Complications (SCs, WI, \& median blood loss): } \\
14.3 \%, 11.4 \%, 1500 \mathrm{ml}\end{array}$ \\
\hline \multirow{4}{*}{$\begin{array}{l}\text { Zairi et } \\
\text { al., } \\
2012\end{array}$} & \multirow[t]{4}{*}{ II } & PCS, 10 patients & \multirow[t]{2}{*}{ NO (I/M F): $80 \%$} \\
\hline & & Tumor origin: mixed, lung (40\%) most common & \\
\hline & & Tumor location: T (70\%) & \multirow{2}{*}{$\begin{array}{l}\text { PA (PR): } 100 \% \\
\text { Survival: } 60 \% \text { patients survived at } 6 \text { mos }\end{array}$} \\
\hline & & Procedure: all patients had minimally invasive pst TC & \\
\hline \multirow{5}{*}{$\begin{array}{l}\text { Cho \& } \\
\text { Sung, } \\
2009\end{array}$} & \multirow[t]{5}{*}{ III } & RCS, 21 patients & NO (I F): 33\% \\
\hline & & Tumor origin: mixed, lung (19\%), prostate $(19 \%)$, colon $(14 \%)$ most common & Median survival: 8.9 mos \\
\hline & & Tumor location: T \& L & RR: $14 \%$ \\
\hline & & \multirow[t]{2}{*}{ Procedure: all 21 patients had PTA w/ pst instrumentation } & $\begin{array}{l}\text { PA (PR): } 95.2 \% \text {; mean preop VAS } 6.82 \pm 2.13 \text { vs } \\
\text { postop VAS } 3.61 \pm 1.01\end{array}$ \\
\hline & & & Complications (WI \& MBL): 9.5\% \& $1400 \mathrm{ml}$ \\
\hline \multirow{5}{*}{$\begin{array}{c}\text { Deutsch } \\
\text { et al., } \\
2008\end{array}$} & \multirow[t]{5}{*}{ III } & RCS, 8 patients & NO (I Nurick): $62.5 \%(5 / 8)$ \\
\hline & & Tumor origin: mixed, breast (38\%) \& lung (38\%) most common & Survival: $37.5 \%$ (3/8) survive $>12$ mos \\
\hline & & Tumor location: T (100\%) & RR: $0 \%$ \\
\hline & & \multirow{2}{*}{$\begin{array}{l}\text { Procedure: all patients had minimally invasive posterolat vertebrectomy \& } \\
\text { decompression }\end{array}$} & PA (PR): $62.5 \%(5 / 8)$ \\
\hline & & & Complications (SCs \& MBL): 0\% \& $227 \mathrm{ml}$ \\
\hline \multirow{4}{*}{$\begin{array}{c}\text { Kamat } \\
\text { et al., } \\
2008\end{array}$} & \multirow[t]{4}{*}{ III } & RCS, 8 patients & NO (I/M F): $100 \%$ \\
\hline & & Tumor origin: mixed, breast (25\%) \& renal (25\%) most common & RR: $0 \%$ \\
\hline & & Tumor location: T (100\%) & PA (PR): $88 \%$ \\
\hline & & $\begin{array}{l}\text { Procedure: all patients had single-stage PTA w/ 3-column stabilization } \\
\text { using titanium cage }\end{array}$ & Complications (SCs \& MBL): 0\% \& $1900 \mathrm{ml}$ \\
\hline \multirow{4}{*}{$\begin{array}{l}\text { Chen et } \\
\text { al., } \\
20078\end{array}$} & \multirow[t]{4}{*}{ III } & RCS, 31 patients & NO (WPO \& I F): 74\% (23/31) \& 80\% \\
\hline & & Tumor origin: lung & Median survival: 8.8 mos \\
\hline & & Tumor location: T (77\%) or L (23\%) & RR: $3.2 \%(1 / 31)$ \\
\hline & & Procedure: 28 of 31 patients had PTA & SCs: $25.8 \%(8 / 31)$ \\
\hline \multirow{4}{*}{$\begin{array}{l}\text { Chen et } \\
\text { al., } \\
20079\end{array}$} & \multirow[t]{4}{*}{ III } & RCS, 23 patients & NO (WPO \& I F): $73.9 \%$ (17/23) \& 82.6\% (19/23) \\
\hline & & Tumor origin: mixed, lung (69.5\%) most common & Median survival: 11.3 mos \\
\hline & & Tumor location: T (100\%) & RR: $4.3 \%(1 / 23)$ \\
\hline & & $\begin{array}{l}\text { Procedure: all } 23 \text { patients had PTA partial corpectomy w/o ant vertebral } \\
\text { reconstruction }\end{array}$ & $\begin{array}{l}\text { Complications (SCs \& MBL): } 30.4 \% \text { (7/23) \& } \\
1387 \mathrm{ml}\end{array}$ \\
\hline \multirow{4}{*}{$\begin{array}{c}\text { Senel } \\
\text { et al., } \\
2007\end{array}$} & \multirow[t]{4}{*}{ III } & RCS, 7 patients & NO (NI): unchanged \\
\hline & & $\begin{array}{l}\text { Tumor origin: mixed, carcinoma (43\%), prostate (23\%), thyroid (14\%), \& } \\
\text { adenocarcinoma (14\%) }\end{array}$ & Survival: $43 \%$ (3/7) survive $>12$ mos \\
\hline & & Tumor location: L (57\%) \& T (43\%) & PA (PR): $100 \%$ \\
\hline & & $\begin{array}{l}\text { Procedure: all } 7 \text { patients had resection via pst transpedicular route w/ } \\
\text { circumferential stabilization w/ ghost screwing }\end{array}$ & Complications (MBL): $485 \mathrm{ml}$ \\
\hline
\end{tabular}


» CONTINUED FROM PAGE 8

TABLE 2. Transpedicular corpectomy studies

\begin{tabular}{|c|c|c|c|}
\hline $\begin{array}{l}\text { Authors } \\
\& \text { Year }\end{array}$ & $\begin{array}{l}\text { Evidence } \\
\text { Class }\end{array}$ & Design \& Procedure & Outcome \\
\hline \multirow{5}{*}{$\begin{array}{l}\text { Bilsky } \\
\text { et al., } \\
2000\end{array}$} & \multirow[t]{5}{*}{ III } & RCS, 25 patients & NO (NI \& WPO): $25 \%$ \& 100\% (9/9) \\
\hline & & \multirow{2}{*}{$\begin{array}{l}\text { Tumor origin: mixed, sarcoma (20\%), renal (16\%), breast (16\%) most com- } \\
\text { mon }\end{array}$} & Median survival: 9.75 mos \\
\hline & & & RR: $8 \%(2 / 25)$ \\
\hline & & \multirow{2}{*}{$\begin{array}{l}\text { Tumor location: } T(84 \%) \& L(16 \%) \\
\text { Procedure: all patients had PTA for spondylectomy, epidural decompres- } \\
\quad \text { sion, \& circumferential fusion }\end{array}$} & PA (PR): $100 \%$ \\
\hline & & & Complications (MBL): $1700 \mathrm{ml}$ \\
\hline \multirow{4}{*}{$\begin{array}{l}\text { Cahill \& } \\
\text { Kumar, } \\
1999\end{array}$} & \multirow[t]{4}{*}{ III } & RCS, 9 patients & NO (WPO): $88 \%$ \\
\hline & & Tumor origin: mixed, lung (33\%) \& colon (22\%) most common & Survival: $88.9 \%$ survive $<6$ mos \\
\hline & & Tumor location: T2-L3 & RR: $11.1 \%(1 / 9)$ \\
\hline & & $\begin{array}{l}\text { Procedure: all patients had single-stage circumferential decompression } \\
\text { (PTA) followed by ant \& pst reconstruction w/ instrumentation }\end{array}$ & PA (PR): $100 \%$ \\
\hline \multirow{4}{*}{$\begin{array}{l}\text { Weller \& } \\
\text { Ros- } \\
\text { sitch, } \\
1995\end{array}$} & \multirow[t]{4}{*}{ III } & RCS, 8 patients & NO (NI): $100 \%(5 / 5)$ \\
\hline & & Tumor origin: mixed, prostate $(50 \%)$ most common & PA (PR): $100 \%$ \\
\hline & & Tumor location: $\mathrm{T}(87.5 \%) \& \mathrm{~L}(12.5 \%)$ & Complications (SCs): $25 \%(2 / 8)$ \\
\hline & & Procedure: all patients had unilat PTA decompression & \\
\hline \multirow{4}{*}{$\begin{array}{l}\text { Eleraky } \\
\text { et al., } \\
2010\end{array}$} & \multirow[t]{4}{*}{ III } & RCS, 8 patients & NO (I/M F): $100 \%$ \\
\hline & & Tumor origin: mixed, colon (29\%) most common & PA (PR): $100 \%$ \\
\hline & & Tumor location: C (100\%) & \\
\hline & & Procedure: 7 of 8 patients had pst TC & \\
\hline \multirow{4}{*}{$\begin{array}{l}\text { Laufer } \\
\text { et al., } \\
2013\end{array}$} & \multirow[t]{4}{*}{ III } & RCS, no comparison, 186 patients (patient overlap w/ Wang et al.) & Total local progression: $16.4 \%$ at $1 \mathrm{yr}$ after SRS \\
\hline & & Tumor origin: mixed, renal $(22 \%)$, sarcoma $(18 \%), \&$ prostate $(13 \%)$ & $\begin{array}{l}\text { Local progression: } 4.1 \% \text { at } 1 \mathrm{yr} \text { after high-dose } \\
\text { hypofractionated SRS; } 22.6 \% \text { at } 1 \mathrm{yr} \text { after low- } \\
\text { dose hypofractionated SRS }\end{array}$ \\
\hline & & Tumor location: C (12\%), T (63\%), \& L (25\%) & \\
\hline & & $\begin{array}{l}\text { Procedure: all patients had single-stage PTA to decompress spine circum- } \\
\text { ferentially \& place instrumentation }\end{array}$ & \\
\hline
\end{tabular}

SPLV = single-stage posterolateral vertebrectomy; $\mathrm{TC}$ = transpedicular corpectomy; $\mathrm{Wl}=$ wound infection.

assistance of a cane; thus, neurological improvement was $100 \%$. Cahill and $\operatorname{Kumar}^{5}$ (9 patients) specifically used a single midline posterior approach to perform single-stage circumferential decompression of the cord followed by anterior and posterior reconstruction; they reported one neurological outcome (WPO: 88\%). Lastly, Eleraky et al. ${ }^{13}$ (8 patients) used a posterior transpedicular corpectomy for malignant cervical spine tumors in 7 patients and reported that all 7 improved or maintained their Frankel grade of function $(100 \%)$.

None of these studies stratified survival based on tumor pathology. Two of the prospective studies reported outcomes: Street et al. noted that $75 \%$ of patients were alive at 6 months, ${ }^{32}$ and Wang et al. noted an overall median survival of 7.7 months..$^{33}$ Seven of the 11 retrospective studies reported survival outcomes as overall median survival time (11.3 months, ${ }^{9} 9.75$ months, ${ }^{4} 8.9$ months, ${ }^{10}$ 8.8 months $^{8}$ ), survival at the 12-month follow-up (43\%, ${ }^{30}$ $37.5 \%{ }^{12}$ ), and survival at 6 months $(88.9 \%) .{ }^{5}$ Only 9 of the 14 studies reported RRs. Two of the prospective studies reported RRs of $11 \%$ and $2.4 \% .{ }^{32}$ Seven of the retrospective studies reported RRs of $14 \%,{ }^{10} 11.1 \%,{ }^{5} 8 \%,{ }^{4} 4.3 \%,{ }^{9} 3.2 \%,{ }^{8}$ and $0 \% .^{12,18}$
Pain palliation outcomes were reported in 11 of the 14 studies. In all 3 prospective studies, the outcome measured was pain relief $\left(100 \%{ }^{32,38}\right.$ and $\left.96 \% \%^{33}\right)$. Eight of the 11 retrospective studies reported pain relief $(100 \%, 4,5,13,30,34$ $95.2 \%,{ }^{10} 88 \%,{ }^{18}$ and $62.5 \%{ }^{12}$ ). Laufer et al. ${ }^{20}$ described the clinical outcomes and local tumor control for spinal metastases following "separation surgery" and SRS. These authors found that the incidence of local progression was $16.4 \%$ at 1 year after SRS and was improved with highdose hypofractionated SRS ( $4.1 \%$ cumulative incidence of local progression at 1 year, HR 0.12, $\mathrm{p}=0.04$ ) as opposed to low-dose hypofractionated SRS (22.6\% local progression at 1 year, HR 1). The median follow-up was 7.6 months (range 1.0-66.4 months). ${ }^{20,21}$ The pain, functional, and neurological results of posterolateral decompression and stabilization had been analyzed and reported in an earlier publication.

Complication outcomes were reported in 10 of the 14 studies. In 2 of the prospective studies, SCs were reported $\left(26 \%,{ }^{32} 14.3 \%{ }^{33}\right)$. Wang et al..$^{33}$ also described a median blood loss of $1500 \mathrm{ml}$ and wound infection rate of $11.4 \%$. Eight of the 11 retrospective studies reported complication outcomes such as SCs $\left(30.4 \%,{ }^{8} 25.8 \%,{ }^{9} 25 \%,{ }^{34}\right.$ 
$\left.0 \%{ }^{12,18}\right)$, wound infection rates $\left(9.5 \%{ }^{10}\right)$, and mean blood loss (1900 ml, ${ }^{18} 1700 \mathrm{ml},{ }^{4} 1400 \mathrm{ml},{ }^{10} 1387 \mathrm{ml},{ }^{9} 485 \mathrm{ml},{ }^{30}$ $227 \mathrm{ml}^{12}$ ). Authors in all 14 studies reported performing a PTA based on the location of the tumor and the surgeon's familiarity with the approach and reconstructive options. $^{4,5,8-10,12,13,18,20,30,32-34,38}$ A posterior transpedicular approach with instrumentation was used in 7 studies to stabilize the spine..$^{4,5,10,18,20,30,33}$ Deutsch et al. reported that a PTA was also used over an anterior approach owing to age, comorbidities, and limited life expectancies. ${ }^{12}$

\section{Costotransversectomy}

Of the 34 publications selected for this review, 4 used a posterolateral costotransversectomy approach (PCT; Table 3). These papers provided results on neurological outcomes, survival, recurrence, pain, and complication rates. There was 1 prospective cohort trial, ${ }^{32} 1$ retrospective case-control study, ${ }^{35}$ and 2 retrospective case series. ${ }^{11,23}$ Class I evidence on the use of PCT was not available from any of the selected articles.

As regards neurological outcomes, Class II evidence was available and provided by the prospective study by Street et al. ${ }^{32}$ As previously mentioned, Street et al. (42 patients) evaluated single-stage posterolateral vertebrectomy for disease of the lumbar spine or combined bilateral costotransversectomies in the thoracic spine. Their study was selected as evidence supporting both PTA and PCT because they used a combined approach and because of the limited available literature on PCT approaches for metastatic spine disease. The neurological outcome reported was neurological improvement (100\%). Class III evidence was provided by the 3 retrospective studies. In a retrospective comparison study, Wiggins et al. ${ }^{35}$ evaluated outcomes after performing 29 PCTs (Group 1) and 18 thoracolumbar or combined approaches (Group 2) as initial operations for thoracic neoplasms. The outcomes reported were mean Frankel grade at discharge (4.1 vs 4.7, respectively, $\mathrm{p}=0.74$ ) and mean ASIA motor score at discharge (90.4 [range 50-100] vs 98.3 [range 75-100], respectively, $\mathrm{p}=0.04)$. Both of the retrospective case series addressing PCT reported neurological outcomes. In the study by North et al. ${ }^{23}$ (61 patients), 3 patients underwent a PCT. Although this study is repeated in this review, we decided to include it given the limited available literature on PCT. The outcome of the surgical management for the PCT subgroup of patients was not reported; however, North et al. did report overall neurological outcomes for WPO (96.7\%) and the WPO at 6 months $(81 \%)$. These authors also stratified ambulatory status based on cancer type and reported that ambulatory status endured the longest in breast cancer patients $(p=0.013) .{ }^{23}$ Cybulski et al. ${ }^{11}$ (15 patients) conducted spinal cord decompression via modified PCT approach combined with posterior instrumentation for management of metastatic neoplasms of the thoracic spine. The neurological outcome reported was WPO (80\%). ${ }^{11}$

As regards survival outcomes, 3 of the 4 studies reported data. In the prospective study, $75 \%$ of the patients were alive at the 6-month follow-up and $50 \%$ survived for more than 12 months postoperatively. ${ }^{32}$ The 2 retrospective case series also reported survival outcomes. Cybulski et al. re- ported that $53 \%$ lived longer than 12 months, ${ }^{11}$ and North et al. noted an overall median survival of 10 months. ${ }^{23}$ However, North and colleagues also stratified survival based on tumor pathology and reported that the median survival ranged from 1.7 years in patients with breast cancer to 3 months in lung cancer patients. ${ }^{23}$ As regards the RR, only 1 of the 4 studies reported this outcome; Street et al. reported the only case of recurrence, in which 1 patient had a gastrointestinal adenocarcinoma who had received preoperative RT. ${ }^{32}$

As for pain palliation outcomes, 3 of the 4 papers reported data. In the prospective study, all patients had a statistically significant decrease in the subjective reporting of pain. ${ }^{32}$ The mean preoperative VAS score was 9.94 and reduced to 4.3 postoperatively. The 2 retrospective case series reported pain relief in $56 \%{ }^{23}$ and $73 \% \%^{11}$ of treated patients. Surgical complication rates were reported by all 4 studies. The prospective study reported $26 \% .{ }^{32}$ The retrospective case-control study reported $38 \%$ for Group 1 versus $39 \%$ for Group $2(\mathrm{p}=0.95) .{ }^{35}$ The 2 retrospective case series reported $8.1 \%$ and $7 \% .^{11}$

The PCT approach was used in these studies because of tumor location, ,11,23,32,35 severity of disease, patient health, ${ }^{11,23,32,35}$ surgeon's familiarity with the approach and reconstructive options, ${ }^{11,23,32,35}$ and patient comorbidities. ${ }^{11,32,35}$ In Wiggins et al., PCT was selected if the tumor extended into the posterior elements or paraspinal musculature. ${ }^{35}$ However, a thoracolumbar or combined approach was selected if the tumor had direct extension anterior to the spine or through the pleura. Posterolateral costotransversectomy was also elected if a patient had multiple levels of disease or noncontiguous disease, if the surgeon believed that anterior stabilization was not going to restore spinal stability after tumor resection, if patients had significant medical comorbidities, or if patients could not tolerate a thoracotomy. ${ }^{35}$

\section{Summary and Discussion}

\section{Posterior Laminectomy With and Without Instrumentation}

Among the studies investigating PL either with or without instrumentation, Class II evidence was available from the RCT by Young et al. ${ }^{37}$ and 2 prospective case series conducted by Fuentes et al. ${ }^{14}$ and Mühlbauer et al. ${ }^{22}$ Class III evidence was available from 13 retrospective case series.

\section{Neurological Improvement and Pain Palliation}

Class II data were provided by Young et al. ${ }^{37}$ for laminectomy plus RT versus RT alone with regard to neurological improvement (Table 4). In short, laminectomy added to RT provided no additional benefit compared with RT alone for either neurological status or pain. Class II evidence on neurological improvement and pain palliation for laminectomy with instrumentation was provided by both prospective case series reported by Fuentes et al. ${ }^{14}$ and Mühlbauer et al. ${ }^{22}$ Both studies reported neurological improvement; however, only Fuentes et al. reported on pain palliation. In addition, all 14 retrospective case series addressing posterior surgical intervention reported some form of neurological outcome. Among these 14 
TABLE 3. Costotransversectomy studies

\begin{tabular}{|c|c|c|c|}
\hline $\begin{array}{l}\text { Authors } \\
\& \text { Year }\end{array}$ & $\begin{array}{l}\text { Evidence } \\
\text { Class }\end{array}$ & $\begin{array}{l}\text { Design \& } \\
\text { Procedure }\end{array}$ & Outcome \\
\hline \multirow{5}{*}{$\begin{array}{l}\text { Street } \\
\text { et al., } \\
2007\end{array}$} & \multirow[t]{5}{*}{ II } & PCS, nonrandomized, 42 patients & NO (NI): $100 \%$ \\
\hline & & $\begin{array}{l}\text { Tumor origin: mixed, breast (21\%), kidney (19\%), \& lung (14\%) } \\
\text { most common }\end{array}$ & Survival: $75 \%$ survived at 6 mos, $50 \%$ survived $>12$ mos \\
\hline & & Tumor location: T (81\%) \& L (19\%) & RR: $2.4 \%$ \\
\hline & & \multirow[t]{2}{*}{ Procedure: all patients had SPLV plus PCT } & PA (PR): $100 \%$ \\
\hline & & & SCs: $26 \%$ \\
\hline \multirow[t]{4}{*}{$\begin{array}{l}\text { Wiggins } \\
\text { et al., } \\
2001\end{array}$} & \multirow[t]{4}{*}{ III } & $\begin{array}{l}\text { Retrospective comparison case series, } 47 \text { patients, grouped into } \\
\text { either surgical intervention w/ PCT (Group 1, } 29 \text { patients), or } \\
\text { thoracolumbar or combined treatment (Group 2, } 18 \text { patients) }\end{array}$ & $\begin{array}{l}\text { NO (mean Frankel \& mean ASIA): } 4.1 \text { (Group 1) vs } 4.7 \text { (Group } \\
\text { 2), } p=0.74 ; 90.4 \text { (Group 1) vs } 98.3 \text { (Group 2), } p=0.04\end{array}$ \\
\hline & & $\begin{array}{l}\text { Tumor origin: mixed, lung (27.2\%), kidney }(22.7 \%) \text {, \& breast } \\
(18 \%) \text { most common }\end{array}$ & SCs: $38 \%$ (Group 1) vs 39\% (Group 2), $p=0.95$ \\
\hline & & Tumor location: T (79\%) \& upper L (21\%) most common & \\
\hline & & $\begin{array}{l}\text { Procedure: all } 29 \text { patients in Group } 1 \text { had PCT w/ reconstruction } \\
\text { using tibia fresh-frozen allograft or a vertical titanium mesh } \\
\text { cage filled w/ MMA }\end{array}$ & \\
\hline \multirow{4}{*}{$\begin{array}{l}\text { North et } \\
\text { al., } \\
2005\end{array}$} & \multirow[t]{4}{*}{ III } & RCS, 61 patients & $\begin{array}{l}\text { NO (WPO): } 96.7 \% \text {, ambulatory status endured significantly } \\
\text { longest in patients w/ breast cancer }(p=0.013)\end{array}$ \\
\hline & & Tumor origin: mixed, breast (18\%) \& lung (16.4\%) most common & $\begin{array}{l}\text { Median survival: } 10 \text { mos; survival stratified based on tumor } \\
\text { identity \& median survival ranged from } 1.7 \text { yrs in patients } \\
\text { w/ breast cancer to } 3 \text { mos in those w/ lung cancer }\end{array}$ \\
\hline & & Tumor location: T (47\%), L (32\%), \& C (21\%) & PA (PR): $56 \%$ \\
\hline & & $\begin{array}{l}\text { Procedure: } 24 \text { patients had PL \& } 13 \text { had PL w/ fusion or place- } \\
\text { ment of instrumentation }\end{array}$ & Complications (SCs \& IODs): $8.1 \%$ \& 2 \\
\hline \multirow{4}{*}{$\begin{array}{l}\text { Cybulski } \\
\text { et al., } \\
1991\end{array}$} & \multirow[t]{4}{*}{ III } & RCS, 15 patients & NO (WPO): $80 \%$ \\
\hline & & Tumor origin: mixed, lung (33\%) \& breast $(20 \%)$ most common & Survival: $53 \%>12$ mos \\
\hline & & Tumor location: T (100\%) only & PA (PR): $73 \%$ \\
\hline & & $\begin{array}{l}\text { Procedure: all } 15 \text { patients had spinal canal decompression via } \\
\text { modified PCT approach; however, group of } 10 \text { patients also } \\
\text { received additional stabilization }\end{array}$ & SCs: $7 \%$ \\
\hline
\end{tabular}

MMA = methylmethacrylate.

studies, the most common neurological outcome reported was neurological improvement. In some studies patients showed improvement in Frankel, ASIA, or Nurick grades, which also counted as neurological improvement. Overall, in the retrospective case series, neurological improvement ranged from $22 \%$ to $95 \%$, with a median of $71.75 \%$ (Fig. $1)$. The second most common neurological outcome was WPO, which ranged from $70 \%$ to $97 \%$ with a median of $83.5 \%$ (Fig. 2). The third most common neurological outcome was NAWPO, which ranged from $52 \%$ to $78 \%$ with a median of $71.1 \%$. Hirabayashi et al. was the only study to stratify neurological outcome in terms of LWPO based on cancer type: myeloma (median 44.1 months), prostate carcinoma (22.6 months), thyroid carcinoma (21.4 months), lung carcinoma (14.0 months), and liver carcinoma (7.9 months). ${ }^{15}$ These authors also reported that patients with "favorable" primary tumors had a longer median ambulation time (22.4 months) than those with "unfavorable" tumors $(6.9$ months; $\mathrm{p}<0.0001) .{ }^{15}$ Only 8 of the retrospective case series reported outcomes addressing pain palliation, and the most common was the percent of patients that experienced pain relief, which ranged from $56 \%$ to $100 \%$ with a median of $77.65 \%$ (Fig. 3).

\section{Survival Outcomes and Rates of Recurrence and Complications}

Young et al. ${ }^{37}$ noted a mean survival of 27.5 weeks following laminectomy plus RT compared with 23.4 weeks after RT alone (Table 4). However, no statistical analysis was provided; therefore, no conclusions could be reached with these data. Class II evidence of survival outcomes was provided by the prospective case series by Mühlbauer et al., ${ }^{22}$ who reported a mean survival of 10 months. These 2 prospective studies had $0 \%$ reported surgical complications. In addition, 12 of the retrospective case series addressing the posterior approach surgical intervention reported survival outcomes, most often as the median survival time, which ranged from 1.5 to 17 months with a median of 10.3 months (Fig. 4). The next most common outcome was mean survival time, which ranged from 10.4 to 19.2 months with a median of 14.8 months. Survival was stratified by tumor pathology in 2 studies. North et al. ${ }^{23}$ reported that the overall median survival was 10 months, and after stratifying for survival based on tumor pathology, they reported a median survival of 1.7 years in breast cancer patients and 3 months in lung cancer patients. Although Hirabayashi et al. reported that the overall median survival for patients postoperation 
TABLE 4. Posterior laminectomy literature outcomes summary

\begin{tabular}{|c|c|c|}
\hline Authors, Year, \& Study Type & Class of Evidence & Outcome \\
\hline \multicolumn{3}{|l|}{ Neurological improvement } \\
\hline Young et al., 1980 (RCT) & II & WPO: surgery $=44 \%$ vs radiation $=54 \%$ \\
\hline Fuentes et al., 2007 (PCS) & II & I/M F: $100 \%$ \\
\hline Mühlbauer et al., 2000 (PCS) & II & NI \& NAWPO: $82 \%$ \& 70\% \\
\hline All PL RCS (14 studies) & III & $\begin{array}{l}\text { NI: } 22 \%-95 \% \text { (median } 71.75 \% \text { ) } \\
\text { WPO: } 70 \%-97 \% \text { (median } 83.5 \% \text { ) } \\
\text { NAWPO: } 52 \%-78 \% \text { (median } 71.1 \% \text { ) }\end{array}$ \\
\hline Hirabayashi et al., 2003 (RCS) & III & $\begin{array}{l}\text { LWPO, stratified: longest median ambulation time, myeloma } 44.1 \text { mos; shortest } \\
\text { median, liver } 7.9 \text { mos }\end{array}$ \\
\hline \multicolumn{3}{|l|}{ Pain alleviation } \\
\hline Young et al., 1980 & II & $6 / 14$ w/ preop pain (43\%) in surgical group had significant pain reduction \\
\hline Fuentes et al., 2007 & II & $100 \%$ patients w/ reduced VAS scores \\
\hline All PL RCS (8 studies) & III & PR: $56 \%-100 \%$ (median $77.65 \%$ ) \\
\hline \multicolumn{3}{|l|}{ Survival outcome } \\
\hline Young et al., 1980 & II & Mean survival: 27.5 wks \\
\hline Mühlbauer et al., 2000 & II & Median survival: 10 mos (approx 300 days) \\
\hline All RCSs (10 studies) & III & Median survival: $1.5-17$ mos (median 10.3 mos) \\
\hline Hirabayashi et al., 2003 & III & $\begin{array}{l}\text { Stratified by pathology: longest median, myeloma } 44.4 \text { months; shortest median, } \\
\text { stomach } 2.1 \text { mos }\end{array}$ \\
\hline \multicolumn{3}{|l|}{ Complications } \\
\hline Fuentes et al., 2007 & II & SCs: $0 \%$ \\
\hline Mühlbauer et al., 2000 & II & SCs: $0 \%$ \\
\hline All PL RCS (9 studies) & III & SCs: $0 \%-25 \%$ (median $13.5 \%$ ) \\
\hline \multicolumn{3}{|l|}{ Recurrence } \\
\hline All RCS (8 studies) & III & RR: $2.5 \%-21 \%$ (median 6\%) \\
\hline
\end{tabular}

Approx = approximately.

was 10.6 months, these authors also stratified survival outcomes based on tumor pathology as follows: myeloma (44.4 months), thyroid carcinoma (25.5 months), prostate carcinoma (20.1 months), breast carcinoma (18.6 months), rectal carcinoma (15.2 months), primary tumor in the pancreas (5.7 months), esophagus (4.7 months), and stomach

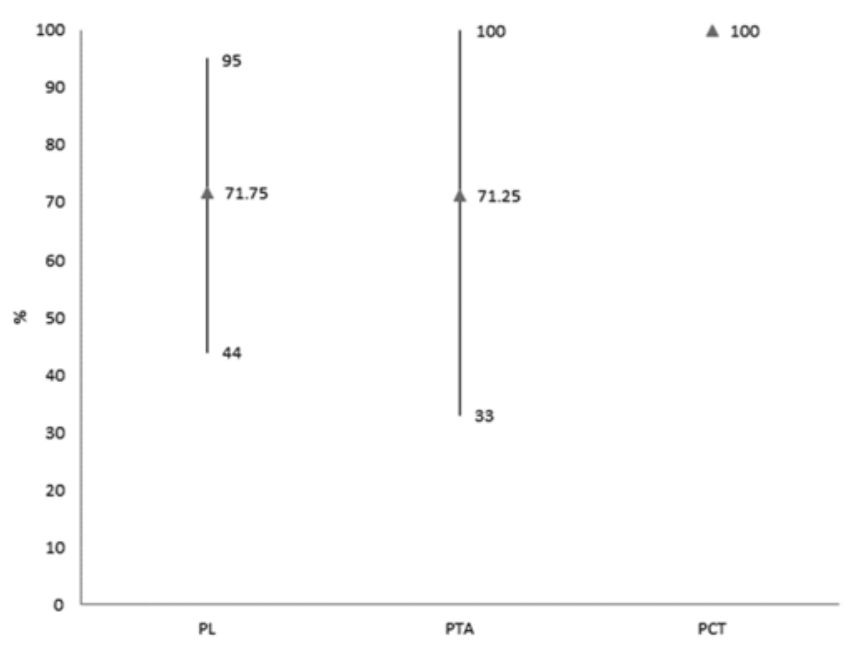

FIG. 1. Percent of patients with neurological improvement, according to procedure performed.
(2.1 months). Patients with myeloma, thyroid carcinoma, or prostate carcinoma had significantly longer survival than patients with primary tumors in the esophagus, liver, lung, or pancreas $(p<0.05) .{ }^{15}$ This was consistent with the idea that patient survival is intimately correlated to the origin of the primary tumor. Eight of the retrospective case series reported recurrence outcomes, and the most

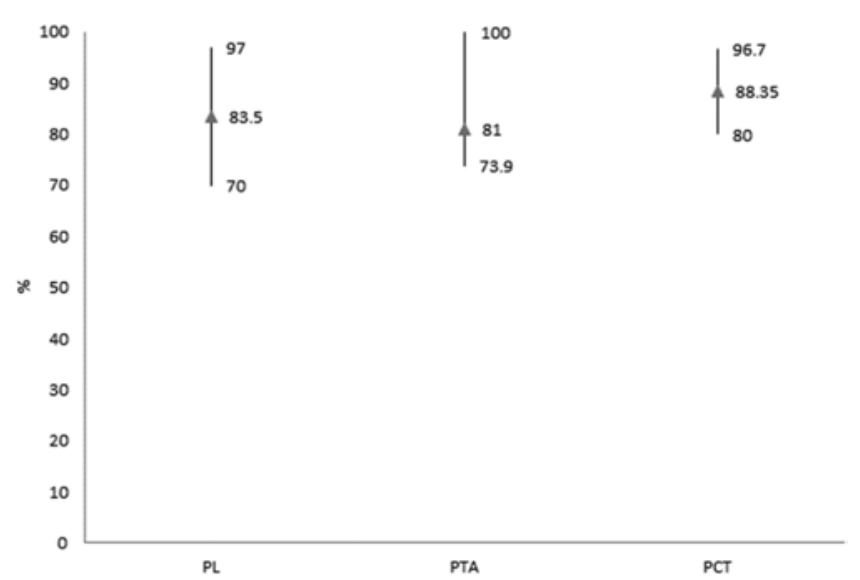

FIG. 2. Percent of patients that could walk postoperation, according to procedure performed. 


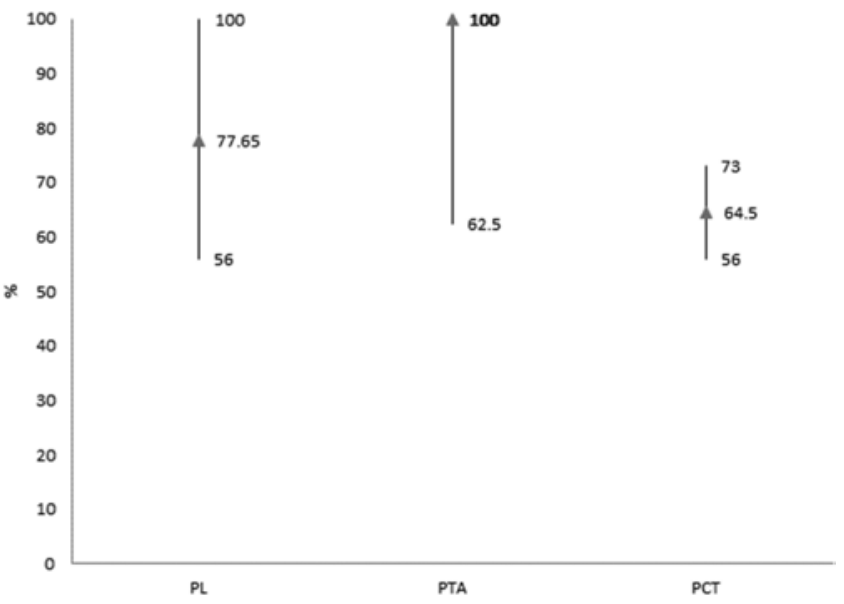

FIG. 3. Percent of patients that had pain relief, according to procedure performed.

common was the RR in patients, which ranged from $2.5 \%$ to $21 \%$ with a median of $6 \%$ (Fig. 5). None of the studies reported the RR stratified by tumor pathology. Only 9 of the retrospective case series reported complication outcomes, most commonly the percentage of patients that experienced SCs, which ranged from 0 to $25 \%$ with a median of $13.5 \%$ (Fig. 6).

In summary, Class II data from Young et al. ${ }^{37}$ suggested that laminectomy without instrumentation did not provide any significant benefit when combined with RT compared with RT alone. However, other Class II data from prospective cohorts demonstrated that laminectomy combined with instrumentation for stabilization could improve neurological outcomes ${ }^{14,22}$ and pain. ${ }^{14}$ However, these prospective studies did not have control groups, so again conclusions were limited. Interestingly, one of the retrospective studies stratified neurological improvement according to tumor pathology and found plasmacytomas and hepatocellular carcinomas to be associated with the best and worst neurological prognosis (as indicated by ambulation time after surgery), respectively. ${ }^{15}$ With respect to survival, a total of 14 studies reported survival outcomes

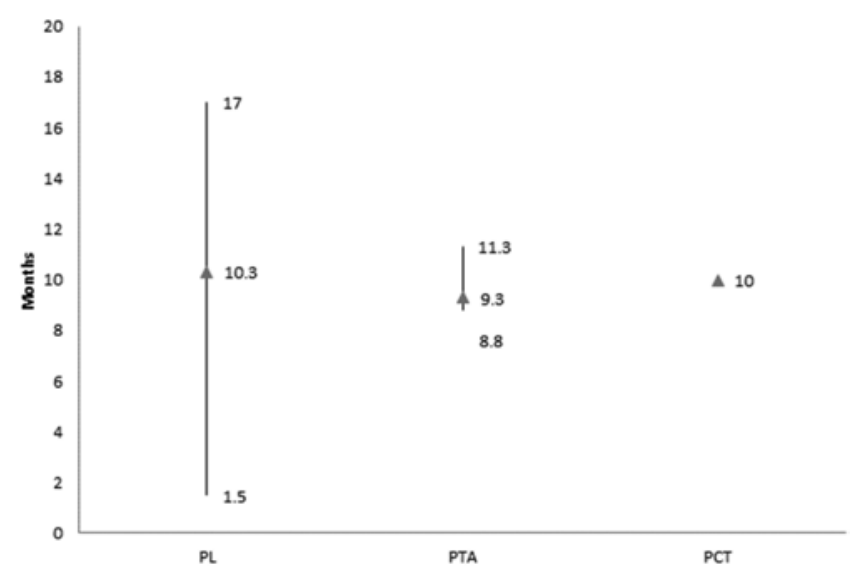

FIG. 4. Median survival of reported patients, according to procedure performed.

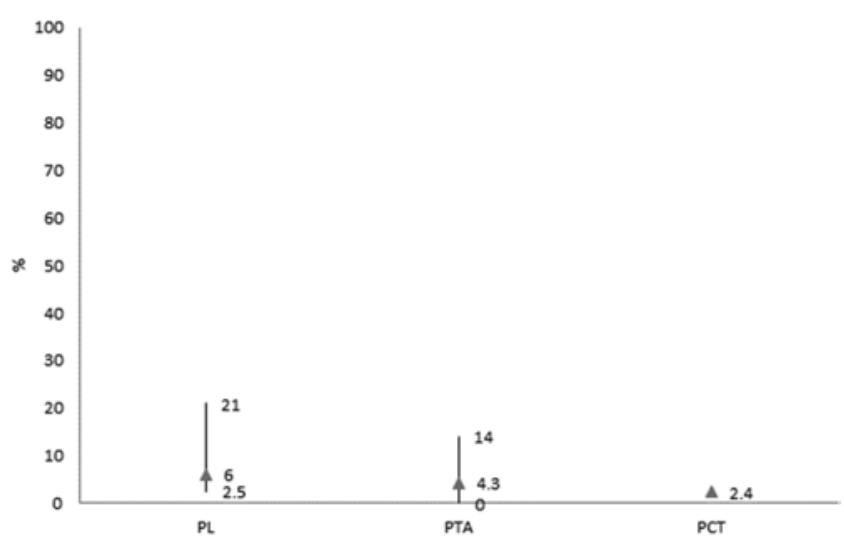

FIG. 5. Percent of patients with tumor recurrence, according to procedure performed.

that varied significantly. A multicenter prospective study conducted by Ibrahim et al. ${ }^{16}$ demonstrated that patients undergoing tumor excision had better survival outcomes than those receiving only palliative therapy. One of the studies stratified survival outcomes based on tumor origin and found that plasmacytomas and stomach cancers were associated with the best and worst prognostic survival outcomes, respectively. ${ }^{15}$ Complication outcomes varied significantly among the different studies, with some authors reporting a complete absence of complications and some reporting a $25 \%$ complication rate. It is possible that this wide range of complication outcomes is associated with the primary tumor pathology, the level approached, and patient comorbidities. All of these factors were not formally assessed in the literature but should be accounted for in future studies that address complications. This is emphasized in the study by Chaichana et al., who stated that nonambulatory patients had an increased rate of postoperative complications. The RRs were also highly variable and difficult to interpret and compare since they were stratified by neither tumor pathology nor the extent of

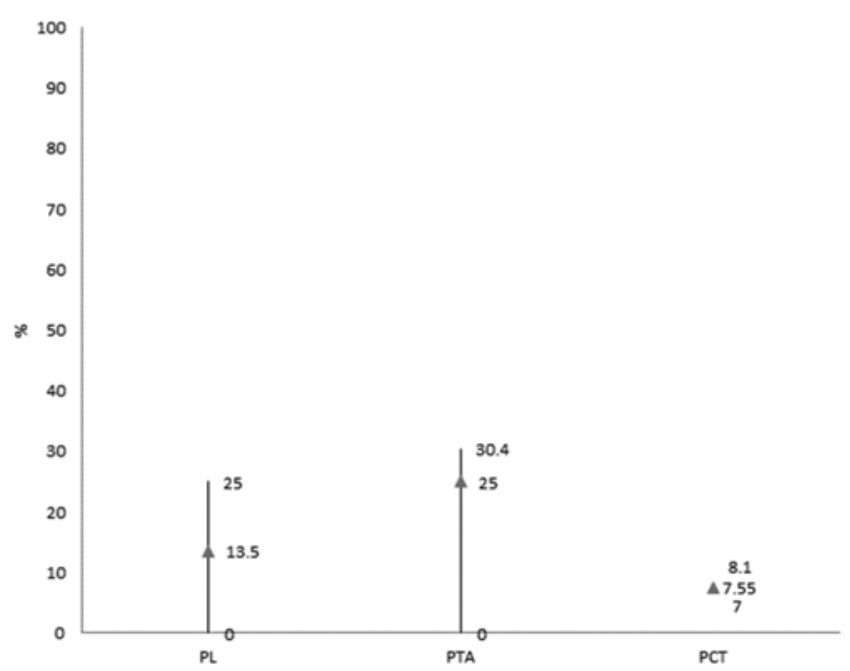

FIG. 6. Percent of patients with surgical complications, according to procedure performed. 
TABLE 5. Transpedicular corpectomy literature outcomes summary

\begin{tabular}{|c|c|c|}
\hline Authors, Year, \& Study Type & Class of Evidence & Outcome \\
\hline \multicolumn{3}{|l|}{ Neurological improvement } \\
\hline Street et al., 2007 (PCS) & ॥ & $\mathrm{Nl}: 100 \%$ \\
\hline Wang et al., 2004 (PCS) & II & NI, NAWPO, \& I/M ASIA: 90\%; 75\%, \& 96\% \\
\hline Zairi et al., 2012 & II & I/M F: $80 \%$ \\
\hline \multirow[t]{2}{*}{ All TC RCS (11 studies) } & \multirow[t]{2}{*}{ IV } & Nl: 33\%-100\% (median 71.25\%) \\
\hline & & WPO: 73.9\%-100\% (median 81\%) \\
\hline \multicolumn{3}{|l|}{ Pain alleviation } \\
\hline Street et al., 2007 & II & PR: $100 \%$ \\
\hline Wang et al., 2004 & II & PR: $96 \%$ \\
\hline Zairi et al., 2012 & II & PR: $100 \%$ \\
\hline All TC RCS (8 studies) & III & PR: $62.5 \%-100 \%$ (median 100\%) \\
\hline \multicolumn{3}{|l|}{ Survival } \\
\hline Street et al., 2007 & II & $75 \%$ survive at 6 mos; $50 \%$ survive at 12 mos \\
\hline Wang et al., 2004 & II & Median survival: 7.7 mos \\
\hline Zairi et al., 2012 & II & $60 \%$ patients survived at 6 mos \\
\hline All TC RCS (7 studies) & III & Median survival: 8.8-11.3 mos (median 9.3 mos) \\
\hline \multicolumn{3}{|l|}{ Complications } \\
\hline Street et al., 2007 & II & SC: $26 \%$ \\
\hline Wang et al., 2004 & II & SC: $14 \%$ \\
\hline All RCS (8 studies) & III & SC: $0 \%-30.4 \%$ (median $25 \%$ ) \\
\hline \multicolumn{3}{|l|}{ Recurrence } \\
\hline Street et al., 2007 & II & RR: $26 \%$ \\
\hline Wang et al., 2004 & $\|$ & RR: $11 \%$ \\
\hline All TC RCS (7 studies) & III & RR: $0 \%-14 \%$ (median $4.3 \%$ ) \\
\hline
\end{tabular}

resection (for example, en bloc or excisional). Given the lack of high-level evidence and adequately powered studies, the magnitude of all outcomes assessed in this review could not be confidently quantified. Thus, all conclusions drawn from the provided data should be carefully integrated with clinical experience and the individual patient when selecting a PL with or without instrumentation for surgical intervention.

\section{Transpedicular Corpectomy}

Among the studies investigating transpedicular corpectomy, Class I evidence was unavailable. Class II evidence supporting the use of PTA was limited to 3 studies by Street et al., ${ }^{32}$ Wang et al., ${ }^{33}$ and Zairi et al. ${ }^{38}$ Street et al. evaluated patients who underwent single-stage posterolateral vertebrectomy combined with PCT, Wang et al. evaluated the use of single-stage PTA with instrumentation for resection of epidural metastatic spine tumors involving the vertebral body with circumferential reconstruction, and Zairi et al. evaluated patients who underwent posterior transpedicular corpectomy. Class III evidence was available from 11 retrospective case series.

\section{Neurological Improvement and Pain Palliation}

Class II evidence on neurological improvement and pain palliation was provided by all 3 prospective case series by Street et al., Wang et al., and Zairi et al. The first
2 studies reported neurological improvements of $100 \% \%^{32}$ and $90 \%, 33$ respectively, and Zairi et al. reported $80 \%$ of patients with improvement in their Frankel grade (Table 5). All 3 studies also reported a high percentage of patients who experienced pain palliation $\left(100 \%{ }^{32,38}\right.$ and $\left.96 \%{ }^{33}\right)$. In addition, all 11 retrospective case series addressing the use of a PTA reported some form of neurological outcome, most commonly neurological improvement. Some studies had patients show improvement in their Frankel, ASIA, or Nurick grades, which counted as neurological improvement. Overall, neurological improvement ranged from $33 \%$ to $100 \%$ with a median of $71.25 \%$ (Fig. 1). The next most common neurological outcome reported was WPO, which ranged from $73.9 \%$ to $100 \%$ with a median of $81 \%$ (Fig. 2). Only 8 of the retrospective case series reported pain palliation, most often the proportion of patients with pain relief, which ranged from $62.5 \%$ to $100 \%$ with a median of $100 \%$ (Fig. 3).

\section{Survival Outcomes and Rates of Recurrence and Complications}

Class II evidence of survival outcomes was reported by the 3 prospective case series. Street et al. reported that $75 \%$ patients survived at 6 months and $50 \%$ survived at 12 months. ${ }^{32}$ Wang et al. reported an overall median survival of 7.7 months. ${ }^{33}$ Zairi et al. reported that $60 \%$ patients survived at 6 months. ${ }^{38}$ However, none of the studies reported survival times stratified by tumor pathology. With respect to recurrence rates, 2 studies described low recurrence 
rates $\left(2.4 \%,{ }^{32} 11 \%{ }^{33}\right)$. In addition, the most common complication outcome reported by 2 of the 3 prospective studies was the proportion of cases with surgical complications $\left(26 \%,{ }^{32} 14 \%{ }^{33}\right)$.

Seven of the 11 retrospective case series utilizing a PTA reported survival outcomes. Unfortunately, none of the authors stratified survival time based on tumor pathology. The most common survival outcome reported was median survival time, which ranged from 8.8 to 11.3 months with a median of 9.3 months (Fig. 4). The next most common outcome was the proportion of patients who survived longer than a year, which ranged from 37.5 to $43 \%$ with a median of $40 \%$. Eight of the retrospective case series reported complication outcomes, most commonly SCs, which ranged from $0 \%$ to $30.4 \%$ with a median of $25 \%$ (Fig. 6). A total of 7 of the retrospective case series reported RRs, which ranged from 0 to $14 \%$ with a median of $4.3 \%$ (Fig. 5). None of the studies reported RRs stratified by tumor pathology.

None of the studies evaluating PTAs reported an absence of neurological improvement. Additionally, among the studies that did formally report pain outcomes (11 studies), all reported significant pain palliation. Therefore, it can be inferred that the posterior approach is a means to achieve both neurological improvement and pain palliation. However, none of the studies stratified neurological outcomes based on tumor pathology. With respect to survival, a total of 10 studies reported survival outcomes that varied significantly. Unfortunately, none of the available studies compared PTA with palliative treatment. Complication outcomes varied significantly among the different studies, with some authors reporting complication rates as low as $0 \%$ and others as high as $30.4 \%$. As previously discussed, numerous factors (for example, tumor pathology) may account for this wide range and should be considered in future studies. Recurrence rate outcomes were also highly variable and difficult to interpret and compare because they were not stratified by tumor origin or by extent of resection (for example, en bloc or excisional). Therefore, given the absence of high-level evidence and adequately powered studies, the magnitude of all outcomes assessed in this review could not be confidently quantified. Therefore, all conclusions drawn from the data provided should be carefully integrated with clinical experience and the individual patient when selecting a posterior transpedicular approach to treat a spinal neoplasm.

\section{Costotransversectomy}

Class II evidence supporting the use of a PCT was provided by Street et al., 32 who described patients who underwent a single-stage posterolateral vertebrectomy combined with PCT. Class III evidence was available from 1 retrospective case-control study and 2 retrospective case series.

\section{Neurological Improvement and Pain Palliation}

Class II evidence on neurological improvement and pain palliation was provided by Street et al., who reported $100 \%$ rates of both neurological improvement and pain palliation (Table 6). In a retrospective comparison study, Wiggins et al. ${ }^{35}$ evaluated outcomes after performing PCT in 29 patients (Group 1) and thoracolumbar or combined approaches in 18 patients (Group 2) as initial operations for thoracic neoplasms. The neurological outcomes reported were mean Frankel grade at discharge (4.1 Group 1 vs 4.7 Group $2, \mathrm{p}=0.74$ ) and mean ASIA motor score at discharge (90.4 [range 50-100] Group 1 vs 98.3 [range 75-100] Group 2, $\mathrm{p}=0.04) .{ }^{35}$ Among the 2 retrospective case series, the most common neurological outcome reported was WPO $\left(96.7 \%,{ }^{23} 80 \%{ }^{11}\right.$; Fig. 2). Pain palliation was reported by the 2 retrospective case series, which reported pain relief $\left(56 \%,{ }^{23} 73 \%{ }^{11} ; 4\right)$.

\section{Survival Outcomes and Rates of Recurrence and Complications}

Class II evidence of survival outcomes was provided by the prospective study by Street et al., who reported that $75 \%$ patients survived at 6 months and $50 \%$ survived at 12 months (Fig. 4). Street et al. also documented the surgical complications rates $(26 \%)$ and recurrence rates $(2.4 \%)$ (Fig. 6). The retrospective comparison study by Wiggins et al. reported the SCs for Group $1(38 \%)$ versus Group 2 $(39 \%, \mathrm{p}=0.95)$. The 2 retrospective case series addressing the PCT approach reported survival outcomes. North et al. did not specifically indicate survival outcomes for the PCT intervention; ${ }^{23}$ however, they did stratify survival time based on tumor pathology (3 months for lung cancer patients and 1.7 years for breast cancer patients), and they reported an overall median survival of 10 months. The other retrospective case series by Cybulski et al. reported that $53 \%$ of patients survived at 12 months. The 2 retrospective case series noted surgical complication rates $\left(8.1 \%,{ }^{23} 7 \%{ }^{11}\right.$; Table 6).

In summary, only 4 of the reviewed studies addressed a PCT approach. All of these studies reported neurological improvement, and among those that formally reported pain outcomes, all reported some pain palliation. This suggests, albeit weakly, that a PCT approach is a means to achieve both neurological improvement and pain alleviation. The studies that reported complication rates and RRs suggested that PCT has a low RR but a wide range of surgical complication rates. It must be emphasized that the studies addressing a PCT approach were very scarce in comparison with those focusing on the PL and PTA approaches. These limitations further decrease the strength of conclusions drawn from the data collected with respect to a PCT approach.

\section{The Role of Posterior Approaches in the Treatment of Metastatic Spine Disease}

Although evidence elucidating the role of different posterior approaches to treat metastatic epidural spine disease was limited in both quality and quantity, a variety of conclusions can be inferred from the data gathered. In terms of neurological improvement, the outcomes did not appear to be clinically significantly different among the different approaches (Fig. 1). Reported pain relief outcomes were nearly identical for PL and PTA; however, PCT appeared to have much lower proportions of pain relief (Fig. 3). However, Class II data provided by Young et al. ${ }^{37}$ suggested that laminectomy without instrumentation generally did not improve outcomes.

Interestingly, reported survival outcomes were higher 
TABLE 6. Costrotransversectomy literature outcomes summary

\begin{tabular}{|c|c|c|}
\hline Authors, Year, \& Study Type & Class of Evidence & Outcome \\
\hline \multicolumn{3}{|l|}{ Neurological improvement } \\
\hline Street et al., 2007 (PCS) & II & $\mathrm{NI}: 100 \%$ \\
\hline Wiggins et al., $2001^{*}$ & III & Mean Frankel: 4.1 (Group 1) vs 4.7 (Group 2); mean ASIA: 90.4 (Group 1) vs 98.3 (Group 2) \\
\hline North et al., 2005 (RCS) & III & WPO: $96.7 \%$ \\
\hline Cybulski et al., 1991 (RCS) & III & WPO: $80 \%$ \\
\hline \multicolumn{3}{|l|}{ Pain alleviation } \\
\hline Street et al., 2007 & II & PR: $100 \%$ \\
\hline North et al., 2005 & III & PR: $56 \%$ \\
\hline Cybulski et al., 1991 & III & PR: $73 \%$ \\
\hline \multicolumn{3}{|l|}{ Survival outcome } \\
\hline Street et al., 2007 & II & $75 \%$ survive at $6 \mathrm{mos} ; 50 \%$ survive at $12 \mathrm{mos}$ \\
\hline North et al., 2005 & III & Median survival: 10 mos \\
\hline North et al., 2005 & III & Stratified based on tumor pathology: lung cancer 3 mos, breast cancer 1.7 yrs \\
\hline Cybulski et al., 1991, stratified & & $53 \%$ survived $>12$ mos \\
\hline \multicolumn{3}{|l|}{ Complications } \\
\hline Street et al., 2007 & II & SCs: $26 \%$ \\
\hline Wiggins et al., 2001 & III & SCs: 38\% (Group 1) vs 39\% (Group 2) \\
\hline North et al., 2005 & III & SCs: $8.1 \%$ \\
\hline Cybulski et al., 1991 & III & SCs: $7 \%$ \\
\hline \multicolumn{3}{|l|}{ Recurrence } \\
\hline Street et al., 2007 & II & $2.4 \%$ \\
\hline
\end{tabular}

* Retrospective comparison case series.

for PL compared with those for both PTA and PCT. This finding is in contrast to the notion that more aggressive circumferential approaches such as PTA and PCT yield better survival outcomes (Fig. 4). Although the difference may appear clinically significant, it is uncertain whether it is statistically significant. Predictably, reported surgical complications were higher for PTA than for PL; however, those reported for PCT appeared to be much lower (Fig. 6). This is counterintuitive as one would expect the more invasive PCT approach to be associated with more frequent surgical complications. This discrepancy is most likely attributable to the scarcity of available outcomes literature on PCT approaches. Reported RRs were congruent with the clinical notion that circumferential decompression (PTA/PCT vs PL) results in more complete tumor resections and thus decreases recurrence. As regards the reported indications for choosing a posterior approach, the majority of authors used a particular posterior approach based on tumor location and the surgeon's familiarity with the approach and reconstructive options.

\section{Study Limitations}

While this study has sought to provide a comprehensive review of the posterior approaches for the treatment of spinal metastatic disease, note that the ability to draw comprehensive conclusions from the results provided in the reviewed studies was limited given the extensive variation in the scales used to report different outcomes. Moreover, a few of the included studies reported on a smaller number of patients, which suggests that the data may not be generalizable to all populations. Additionally, when possible, data from the studies were summarized for the most frequent outcome scales reported. Finally, some studies reported on more than one procedure; thus, data from these studies were used more than once. Even in light of these shortcomings, this review does provide essential information for clinicians.

\section{Key Issues for Future Investigation}

Determining the most appropriate surgical approach for an individual case depends on a number of factors, including tumor pathology, location, and general medical status of the patient. Multiple factors must be considered when determining the appropriate surgical management of MSCC since the presence of epidural metastasis alone does not require an instrumented reconstruction, although the optimal surgical approach should provide adequate exposure to safely remove the lesion. It is difficult to design a study that controls the important variables yet still has a large enough sample size to be of value. Therefore, future studies will be much more viable if they are multicenter trials to improve patient recruitment. There are weaknesses in the current body of literature that future studies will hopefully address. First, most currently available studies are retrospective. Even if randomized trials are difficult to execute, prospective data would be of value. Second, with few exceptions, the current available data represent case series and cohorts without comparison groups. Without a reasonable control group, any firm conclusions are not possible. Hopefully, future studies will provide data to 
better define the roles of the various options now available to surgeons in treating spinal metastases.

\section{Acknowledgments}

Dr. Goodwin is a UNCF Merck Postdoctoral Fellow and has an award from Burroughs Wellcome Fund.

\section{References}

1. American Cancer Society: Cancer Facts \& Figures 2014. Atlanta: American Cancer Society, 2014

2. Bach F, Agerlin N, Sørensen JB, Rasmussen TB, Dombernowsky P, Sørensen PS, et al: Metastatic spinal cord compression secondary to lung cancer. J Clin Oncol 10:17811787,1992

3. Bach F, Larsen BH, Rohde K, Børgesen SE, Gjerris F, BøgeRasmussen T, et al: Metastatic spinal cord compression. Occurrence, symptoms, clinical presentations and prognosis in 398 patients with spinal cord compression. Acta Neurochir (Wien) 107:37-43, 1990

4. Bilsky MH, Boland P, Lis E, Raizer JJ, Healey JH: Singlestage posterolateral transpedicle approach for spondylectomy, epidural decompression, and circumferential fusion of spinal metastases. Spine (Phila Pa 1976) 25:2240-2250, 2000

5. Cahill DW, Kumar R: Palliative subtotal vertebrectomy with anterior and posterior reconstruction via a single posterior approach. J Neurosurg 90 (1 Suppl):42-47, 1999

6. Chaichana KL, Woodworth GF, Sciubba DM, McGirt MJ, Witham TJ, Bydon A, et al: Predictors of ambulatory function after decompressive surgery for metastatic epidural spinal cord compression. Neurosurgery 62:683-692, 2008

7. Chen LH, Niu CC, Fu TS, Lai PL, Wong CB, Chen WJ: Posterior decompression and stabilization for metastatic spine diseases. Chang Gung Med J 27:903-910, 2004

8. Chen YJ, Chang GC, Chen HT, Yang TY, Kuo BI, Hsu HC, et al: Surgical results of metastatic spinal cord compression secondary to non-small cell lung cancer. Spine (Phila Pa 1976) 32:E413-E418, 2007

9. Chen YJ, Hsu HC, Chen KH, Li TC, Lee TS: Transpedicular partial corpectomy without anterior vertebral reconstruction in thoracic spinal metastases. Spine (Phila Pa 1976) 32:E623-E626, 2007

10. Cho DC, Sung JK: Palliative surgery for metastatic thoracic and lumbar tumors using posterolateral transpedicular approach with posterior instrumentation. Surg Neurol 71:424433, 2009

11. Cybulski GR, Stone JL, Opesanmi O: Spinal cord decompression via a modified costotransversectomy approach combined with posterior instrumentation for management of metastatic neoplasms of the thoracic spine. Surg Neurol 35:280-285, 1991

12. Deutsch H, Boco T, Lobel J: Minimally invasive transpedicular vertebrectomy for metastatic disease to the thoracic spine. J Spinal Disord Tech 21:101-105, 2008

13. Eleraky M, Setzer M, Vrionis FD: Posterior transpedicular corpectomy for malignant cervical spine tumors. Eur Spine J 19:257-262, 2010

14. Fuentes S, Métellus P, Pech-Gourg G, Adetchessi T, Dufour $\mathrm{H}$, Grisoli F: [Open kyphoplasty for management of metastatic spine fracture.] Neurochirurgie 53:49-53, 2007 (Fr)

15. Hirabayashi H, Ebara S, Kinoshita T, Yuzawa Y, Nakamura I, Takahashi J, et al: Clinical outcome and survival after palliative surgery for spinal metastases: palliative surgery in spinal metastases. Cancer 97:476-484, 2003

16. Ibrahim A, Crockard A, Antonietti P, Boriani S, Bünger C, Gasbarrini A, et al: Does spinal surgery improve the quality of life for those with extradural (spinal) osseous metastases? An international multicenter prospective observational study of 223 patients. J Neurosurg Spine 8:271-278, 2008
17. Jansson KA, Bauer HC: Survival, complications and outcome in 282 patients operated for neurological deficit due to thoracic or lumbar spinal metastases. Eur Spine J 15:196-202, 2006

18. Kamat A, Gilkes C, Barua NU, Patel NR: Single-stage posterior transpedicular approach for circumferential epidural decompression and three-column stabilization using a titanium cage for upper thoracic spine neoplastic disease: a case series and technical note. Br J Neurosurg 22:92-98, 2008

19. Kondo T, Hozumi T, Goto T, Seichi A, Nakamura K: Intraoperative radiotherapy combined with posterior decompression and stabilization for non-ambulant paralytic patients due to spinal metastasis. Spine (Phila Pa 1976) 33:1898-1904, 2008

20. Laufer I, Iorgulescu JB, Chapman T, Lis E, Shi W, Zhang Z, et al: Local disease control for spinal metastases following "separation surgery" and adjuvant hypofractionated or highdose single-fraction stereotactic radiosurgery: outcome analysis in 186 patients. J Neurosurg Spine 18:207-214, 2013

21. Moussazadeh N, Laufer I, Yamada Y, Bilsky MH: Separation surgery for spinal metastases: effect of spinal radiosurgery on surgical treatment goals. Cancer Contr 21:168-174, 2014

22. Mühlbauer M, Pfisterer W, Eyb R, Knosp E: Noncontiguous spinal metastases and plasmocytomas should be operated on through a single posterior midline approach, and circumferential decompression should be performed with individualized reconstruction. Acta Neurochir (Wien) 142:1219-1230, 2000

23. North RB, LaRocca VR, Schwartz J, North CA, Zahurak M, Davis RF, et al: Surgical management of spinal metastases: analysis of prognostic factors during a 10-year experience. J Neurosurg Spine 2:564-573, 2005

24. Patchell RA, Tibbs PA, Regine WF, Payne R, Saris S, Kryscio RJ, et al: Direct decompressive surgical resection in the treatment of spinal cord compression caused by metastatic cancer: a randomised trial. Lancet 366:643-648, 2005

25. Placantonakis DG, Laufer I, Wang JC, Beria JS, Boland P, Bilsky M: Posterior stabilization strategies following resection of cervicothoracic junction tumors: review of 90 consecutive cases. J Neurosurg Spine 9:111-119, 2008

26. Rades D, Huttenlocher S, Bajrovic A, Karstens JH, Adamietz IA, Kazic N, et al: Surgery followed by radiotherapy versus radiotherapy alone for metastatic spinal cord compression from unfavorable tumors. Int J Radiat Oncol Biol Phys 81:e861-e868, 2011

27. Rompe JD, Hopf CG, Eysel P: Outcome after palliative posterior surgery for metastatic disease of the spine-evaluation of 106 consecutive patients after decompression and stabilisation with the Cotrel-Dubousset instrumentation. Arch Orthop Trauma Surg 119:394-400, 1999

28. Saito T, Kondo T, Hozumi T, Karasawa K, Seichi A, Nakamura K: Results of posterior surgery with intraoperative radiotherapy for spinal metastases. Eur Spine J 15:216-222, 2006

29. Sciubba DM, Gokaslan ZL: Diagnosis and management of metastatic spine disease. Surg Oncol 15:141-151, 2006

30. Senel A, Kaya AH, Kuruoglu E, Celik F: Circumferential stabilization with ghost screwing after posterior resection of spinal metastases via transpedicular route. Neurosurg Rev 30:131-137, 2007

31. Shimizu K, Shikata J, Iida H, Iwasaki R, Yoshikawa J, Yamamuro T: Posterior decompression and stabilization for multiple metastatic tumors of the spine. Spine (Phila Pa 1976) 17:1400-1404, 1992

32. Street J, Fisher C, Sparkes J, Boyd M, Kwon B, Paquette S, et al: Single-stage posterolateral vertebrectomy for the management of metastatic disease of the thoracic and lumbar spine: a prospective study of an evolving surgical technique. J Spinal Disord Tech 20:509-520, 2007

33. Wang JC, Boland P, Mitra N, Yamada Y, Lis E, Stubblefield 
M, et al: Single-stage posterolateral transpedicular approach for resection of epidural metastatic spine tumors involving the vertebral body with circumferential reconstruction: results in 140 patients. Invited submission from the Joint Section Meeting on Disorders of the Spine and Peripheral Nerves, March 2004. J Neurosurg Spine 1:287-298, 2004

34. Weller SJ, Rossitch E Jr: Unilateral posterolateral decompression without stabilization for neurological palliation of symptomatic spinal metastasis in debilitated patients. J Neurosurg 82:739-744, 1995

35. Wiggins GC, Mirza S, Bellabarba C, West GA, Chapman JR, Shaffrey CI: Perioperative complications with costotransversectomy and anterior approaches to thoracic and thoracolumbar tumors. Neurosurg Focus 11(6): 4, 2001

36. Yang SB, Cho W, Chang UK: Analysis of prognostic factors relating to postoperative survival in spinal metastases. J Korean Neurosurg Soc 51:127-134, 2012

37. Young RF, Post EM, King GA: Treatment of spinal epidural metastases. Randomized prospective comparison of laminectomy and radiotherapy. J Neurosurg 53:741-748, 1980

38. Zairi F, Arikat A, Allaoui M, Marinho P, Assaker R: Minimally invasive decompression and stabilization for the management of thoracolumbar spine metastasis. J Neurosurg Spine 17:19-23, 2012

\section{Disclosures}

Dr. Sciubba is a consultant for Medtronic, Globus, DePuy, and Orthofix. Dr. Goodwin is a UNCF Merck Postdoctoral Fellow and has received an award from the Burroughs Wellcome Fund and the Johns Hopkins Neurosurgery Pain Research Institute. Dr. Elder works for the FDA, but this manuscript was prepared independently and entirely as an outside activity at Johns Hopkins. As such, this manuscript represents the views of the authors and should not be construed to represent the FDA's views or policies.

\section{Author Contributions}

Conception and design: Sciubba, Molina, Goodwin, Elder. Acquisition of data: Molina, Goodwin, Elder. Analysis and interpretation of data: Sciubba, Molina, Goodwin, Elder. Drafting the article: Molina, Goodwin, Elder. Critically revising the article: all authors. Reviewed submitted version of manuscript: all authors. Statistical analysis: Molina, Goodwin, Elder. Administrative/technical/material support: Sciubba, Molina, Goodwin, Elder. Study supervision: Sciubba, Molina, Goodwin, Elder.

\section{Correspondence}

Daniel M. Sciubba, Department of Neurosurgery, The Johns Hopkins Hospital, 600 North Wolfe St., Meyer 7-185, Baltimore, MD 21287. email: dsciubb1@jhmi.edu. 